\title{
Estudio, edición y traducción de un inédito burlesco de Antonio de Nebrija: la Malleoli Ascalaphi Cisterciensis Ordinis Commodatarii uita
}

\author{
Pedro MARTín BAÑos \\ IES Carolina Coronado, Almendralejo \\ pmartinbanos@yahoo.es
}

Recibido: 12 de septiembre de 2011

Aceptado: 25 de octubre de 2011

\section{RESUMEN}

El artículo exhuma un texto inédito de Antonio de Nebrija, una Vita burlesca de su primogénito frey Marcelo de Lebrija, que fue comendador de la Orden de Alcántara y llevó una vida mundana y poco ejemplar hasta el momento de su retiro a Brozas (Cáceres), donde radicaba la encomienda. El retiro de frey Marcelo tuvo lugar en 1518, fecha en torno a la que debió de componerse la Vita, de propósito moralizante.

Palabras clave: Antonio de Nebrija. Frey Marcelo de Lebrija. Humanismo. Sátira.

Martín BAÑos, P., «Estudio, edición y traducción de un inédito burlesco de Antonio de Nebrija: la Malleoli Ascalaphi Cisterciensis Ordinis commodatarii uita», Cuad. Fil. Clás. Estud. Lat. 31.2 (2011) 255-291.

\section{Study, Edition and Translation of an unpublished Satire of Antonio de Nebrija: Malleoli Ascalaphi Cisterciensis Ordinis commodatarii uita}

\begin{abstract}
The article exhumes an unpublished text by Antonio de Nebrija, a satirical Vita of his eldest son frey Marcelo de Lebrija, who was a comendador of the Order of Alcántara and led a mundane and little exemplary life until his retreat to Brozas (Cáceres), where the encomienda was located. The retreat of frey Marcelo took place in 1518, and the Vita, which betrays a moralising purpose, was probably composed at around this date.
\end{abstract}

Keywords: Antonio de Nebrija. Frey Marcelo de Lebrija. Humanism. Satire.

MARTín BAÑos, P., «Study, Edition and Translation of an unpublished Satire of Antonio de Nebrija: $M a-$ lleoli Ascalaphi Cisterciensis Ordinis commodatarii uita», Cuad. Fil. Clás. Estud. Lat. 31.2 (2011) 255-291.

Sumario 1. Los manuscritos. 2. Contenido de la Malleoli uita. 3. La Malleoli uita. Intención y fecha. 4. Edición y traducción. 5. Referencias bibliográficas. 
Se brinda en este artículo el texto, con traducción y estudio, de un inédito manuscrito de Antonio de Nebrija: la Malleoli Ascalaphi Cisterciensis ordinis commodatarii uita («Vida de Mazuelo ${ }^{1}$ Ascálafo, comodatario de la Orden del Císter»), una biografía jocosa del primogénito del humanista, frey Marcelo de Lebrija, comendador de la Orden de Alcántara. Es una lástima que no haya podido contarse con esta $\mathrm{Ma}$ lleoli uita en trabajos recientes dedicados a frey Marcelo (Martín Baños 2007, 2008 y 2009), pero lo cierto es que las escasas noticias sobre el opúsculo han pasado prácticamente desapercibidas. En toda la bibliografía nebrisense apenas si se ha reparado en este manuscrito, que siendo en verdad muy fácilmente accesible - una de las copias se encuentra en la Biblioteca Nacional de España: ms. 19018-, ha permanecido a todos los efectos casi oculto a los ojos del investigador. Pese a la existencia de algunas referencias bibliográficas, que van desde Bartolomé J. Gallardo a nuestros días, a la 'opacidad' de la Malleoli uita ha ayudado, y no poco, su desconcertante título, que acumula varias burlas alusivas al biografiado que trataré de desentrañar con calma más adelante. Tampoco ha contribuido a su conocimiento el hecho de que el ms. 19018 de Madrid se encuentre entre los que aún no han sido recogidos en el Inventario general de manuscritos de la Biblioteca Nacional, y aun puede lamentarse que no incluyan rastro alguno de la Vita, como si de una conjura de silencio se tratase, las dos descripciones más recientes de este manuscrito: hablo tanto del magno Iter Italicum de Paul O. Kristeller (Kristeller 1983 y 1989), cuyos volúmenes III y IV sí reavivaron el interés por otros escritos marginales nebrisenses; como de la ficha catalográfica consultable en la página web de la Biblioteca Nacional (www.bne.es)².

A todo esto, la Malleoli uita fue ya descubierta y leída, en la década de los cuarenta del siglo XX, por Pascual Galindo Romeo y Luis Ortiz Muñoz, que llegaron a editar - pero no publicar-su texto. Si he llegado hasta la Vita ha sido precisamente de la mano de estos dos insignes 'nebrijistas', que en 1943 presentaban al premio «Francisco Franco» de Letras, otorgado por el CSIC, «cinco grandes volúmenes encuadernados en folio» de una Aelii Antonii Nebrissensis Opera inedita que logró ver la luz tan solo parcialmente. En diciembre de ese mismo año, recién otorgado el premio, la prensa se hacía eco de la monumental obra de Galindo y Ortiz, y diversas publicaciones especializadas la reseñaban a lo largo de 1944 y $1945^{3}$. La llamada Miscelánea Nebrija, por ejemplo, número especial y conjunto de Emerita y la Revista de

\footnotetext{
${ }^{1}$ De forma seguramente discutible, he optado por verter Malleolus por 'Mazuelo', esto es, 'mazo pequeño', a sabiendas de que la acepción que la RAE recoge de este término ('Mango o mano como de almirez, con que se toca el morterete') es más especializada de la que aquí se requiere. La necesidad de encontrar una traducción para Malleolus ('martillo pequeño') que pueda funcionar como nombre propio me ha llevado hasta este Mazuelo, que al mismo tiempo cumple medianamente bien con la paronomasia latina (Marcellus/Malleolus; Marcelo/Mazuelo) que el propio Nebrija buscó, como se verá en el texto de la Vita que se edita. He preferido no emplear, como hicieron Pascual Galindo y Luis Ortiz (véanse las páginas que siguen), 'Maléolo', cuyo significado actual ('tobillo') es todavía más técnico.

${ }^{2}$ Los volúmenes de Kristeller están en el origen de Gilly (1986 y 1998), artículos en los que se dan a conocer inéditos nebrisenses. Tanto la descripción del ms. 19018 del vol. IV de Kristeller como la del registro catalográfico en línea de la BNE están incompletas, y olvidan la Vita.

${ }^{3}$ Son especialmente útiles la reseña de $A b c$ de 28 de diciembre de 1943, p. 23; y un artículo sin firma de 1944, «Los últimos hallazgos sobre la obra literaria de Nebrija», Revista Nacional de Educación, 41, 86-88.
} 
Filología Española, detallaba en su sección «Crónica» (Miscelánea Nebrija 1945, pp. 308-310) el contenido de esta Opera inedita, y adelantaba un plan de publicación futuro que se esperaba que ocupase nada menos que siete tomos: cuatro consagrados a los estudios bíblicos de Nebrija (Nebrissensis Biblica), y tres a los estudios de carácter filológico (Nebrissensis Philologica). También la edición conmemorativa de la Gramática castellana de 1946, al cuidado de los propios Galindo y Ortiz, daba cuenta de estos siete tomos, que incluso parecen citarse como ya dispuestos para ser llevados a imprenta (Nebrija 1946, I, pp.xiii-xiv y passim) ${ }^{4}$. Desgraciadamente, como digo, de esta ambiciosa Opera solo una ínfima parte conoció la estampa: el volumen II de la serie Nebrissensis Biblica, que apareció en 1950 (Nebrija 1950). El resto debió de sucumbir a las dificultades editoriales de una empresa tan exigente. Voy a centrarme ya en nuestra Malleoli uita, uno de los textos que Galindo y Ortiz prometían imprimir, pero huelga decir que no sería en balde tratar de localizar, si es que no está definitivamente perdido, el original de esta Opera inedita premiada en 1943, que a buen seguro alberga materiales e investigaciones de primer orden ${ }^{5}$.

\section{LOS MANUSCRITOS}

La Malleoli Ascalaphi Cisterciensis ordinis commodatarii uita está incompleta, y se ha conservado en dos manuscritos misceláneos que guardan una estrecha relación entre sí. El primero y más importante de ellos se custodia en la Biblioteca del Real Colegio Seminario del Corpus Christi de Valencia, en su fondo mayansiano (o Biblioteca-Archivo Hispano-Mayansiana): BAHM, ms. 626. El segundo es una copia que reposa en la Biblioteca Nacional de España: BNE, ms. 19018. Estas son sus descripciones:

BAHM, ms. 626

Siglos XVI-XVIII. Facticio (creado ya en el s. XVIII), papel, 128 fols. Enc. pergamino. Tít. del lomo: Papeles varios XXIX.

Hay una foliación moderna a lápiz en la parte inferior derecha. Los fols. 23r-37v tienen foliación propia (¿del siglo XVIII?) (= 1r-23v); y los fols. 52r-57r poseen paginación con la misma letra que el manuscrito (= págs. 1-11), paginación que queda interrumpida pese a que el contenido continúa. Mestre Sanchís atribuye la mano de los fols. 3r-21v y 46r-125r a Juan Antonio Mayans. Los fols. 23r-37v forman un cuaderno distinto, de papel amarillento de 20 x $15 \mathrm{~cm}$ y manchas causadas por tinta ferrogálica, que a menudo dificultan la lectura en el ítem IV; todo el cuaderno es de letra del siglo XVI (salvo los versos del fol. 37r, con mano del siglo XVIII), y lleva al inicio ex libris manuscrito de Agustín Sales, algo cortado por la guillola luz.

${ }^{4}$ Galindo y Ortiz anunciaban asimismo un estudio biográfico complementario que tampoco alcanzó a ver

${ }^{5} \mathrm{Al}$ menos hasta donde he podido indagar, el original no se conserva en los archivos del CSIC, hoy en la Biblioteca Navarro Tomás. También Odriozola, bibliógrafo por excelencia de Nebrija, estaba al tanto del proyecto de Galindo y Ortiz, y dejó escrito que se preparaba una edición de la Malleoli uita (Odriozola 1946, p. 108). 
tina. Según Chabás, tanto la letra como la filigrana, el guante con la estrella, son de fines del siglo XV (Chabás 1903b, p.66). En blanco los fols. 2r-2v, 3v, 13v, 15v, 22v, 37v (=16v), 45r$45 \mathrm{v}(=24 \mathrm{r}-24 \mathrm{v}), 98 \mathrm{r}-99 \mathrm{v}, 119 \mathrm{v}$ y $125 \mathrm{v}-128 \mathrm{v}$.

fol. 3r.: [Índice del manuscrito, que recoge los ítems I, II, III, IV, VII, VIII, IX, XII, XIII, XIV, XV].

I. fols. 4r-13r: ANTONIO DE NEBRIJA: Aelius Antonius Nebrissensis regius Historiographus in Reuchlinum Phorcensem, et Erasmum Roterodamum Quod de Talita in Evangelio Marci, et Tavita in Luca non bene senserunt.

II. fols. 14r-15r: ANTONIO DE NEBRIJA: De magis observatio.

III. fols. 16r-21v: ANTONIO DE NEBRIJA: Epístola del Maestro de Lebrija al Cardenal, quando se avisó, que en la interpretación de las Dicciones de la Biblia no mandasse seguir al Remigio sin que primero viessen su Obra.

fol. 22r: Marco a tinta (¿para título?). Ex libris manuscrito del siglo XVIII en parte superior: Ex libris D. Augustini Salesii, Historici Val. En la parte izquierda del marco, en letra del XVI: Virgo decens coeli quae dulcissimum complexa natum secundas post illum, partes mundi possides: queque tuo sole amicta et lunam sub pedibus habens cum duodecim stellarum corona miseros mortales deo concilias. Respice ${ }^{6}$. En la parte inferior del cuadro: «A».

IV. fols. 23r-36v (=1r-15v): ANTONIO DE NEBRIJA: Aelij Antonij Nebrissensis historiographi regij de liberis educandis libellus ad Michaelem almaçanum.

V. fol. 37r (=16r) CONDE DE VILLAMEDIANA, JUAN DE TASSIS: Soneto (incompleto): «Cenizas que aguardáys aquella trompa | para unir las especies desatadas | con que al Juycio final serán llamadas».

VI. fols. 38r-44v (=17r-23v): ANTONIO DE NEBRIJA: Aelij Antonij nebrissensis Regij historiographi In ascalaphi Maleoli cisterciensis ordinis commodatarij vitam.

VII. fols. 46r-49v: PEDRO JUAN NÚÑEZ: Artificium orationis Ciceronis pro $C$. Rabirio Perduellionis reo.

VIII. fols. 50r-51v: Quaestio de sex generibus colorum.

IX. fols. 52r-76r (= págs. 1-11 hasta 57r, el resto sin paginación): DR. JUAN DEL ESPINO: Apología.

X. fols. 76v-90r: DR. JUAN DEL ESPINO: Antiepitomología.

XI. fols. 91v-97v: DR. JUAN DEL ESPINO: Confessión que hizo el Dotor Juan de Espino en Granada a treinta de setiembre de mil seiscientos quarenta i tres.

XII. fols. 100r-111v: MANUEL DE RODA: Copia de una Carta... sobre la educación de sus sobrinos dirigida a D. Juan Martín.

XIII. fols. 112r-119r: MANUEL DE RODA: Memorial... en satisfación al presentado por los seis colegios Mayores con fecha de veinte i tres de mayo de mil setecientos setenta i tres.

XIV. fols. 120r-123v: Copia de una carta de Roma escrita en el año 1774 (en el índice del fol. 3r: Carta contra una comedia jesuita).

XV. fols. 124r-125r: Antigüedades halladas en el Inventario hecho del Dotor D. Juan de Flores, Prebendado de la Santa Iglesia de Granada (en el índice del fol. 3r: Inventario burlesco de las Antigüedades halladas en poder del Embustero Flores, Granadino).

\footnotetext{
${ }^{6}$ No sé identificar esta ¿oración? a la Virgen, que en parte parafrasea VvLG.apoc.12, 1.
} 
BNE, ms. $19018(M)$

Facticio. Siglo XVIII, 22 x $16 \mathrm{~cm}$, papel, $2+42$ fols. + 2. Enc. pergamino. Tít. del tejuelo (superior): Nebrissensii opuscula duo inedita (tejuelo inferior ilegible).

2 fols. blancos sin numerar al comienzo, y otros 2 al final. Las primeras 27 hojas llevan paginación coetánea en la parte superior: 1-53 (con la pág. 54 en blanco). Las hojas siguientes llevan foliación moderna a lápiz: fols. $1-15$ (fol. 14v en blanco). La hoja 42 (= fol. 15r) es una carta, guillotinada por el margen derecho, afectando levemente al texto, y con el verso en blanco.

I. h. 1-17v (= págs. 1-34): ANTONIO DE NEBRIJA: Aelij Antonij Nebrissensis historiographi regij de liberis educandis libellus ad Michaelem almaçanum. En la parte superior: Ex libris Augustini Vallesij Historici Valentini ${ }^{7}$.

II. h. 18r-27r (= págs. 35-53): ANTONIO DE NEBRIJA: Aelij Antonij nebrissensis Regij historiographi, In ascalaphi Malleoli cisterciensis ordinis commodatarij vitam.

III. h. 28r-41r (= fols. 1r-14r): ANTONIO DE NEBRIJA: Aelij Antonij Nebrissensis Grammatici atque Regij Historiographi de Mensuris Repetitio sexta.

IV. h. 42r (= fol. 15r): JOSÉ EUGENIO DE IRUSTA: Carta ... a D. Fernando Velasco $(3 \text { de agosto de } 1774)^{8}$.

Para la edición de la Malleoli uita me atendré, obviamente, al ms. 626 de Valencia, que transmite la versión más antigua del opúsculo, en tanto que el ms. 19108 de Madrid es un simple traslado del texto valenciano. Es rastreable, de hecho, parte de la historia entrecruzada de ambos manuscritos (a los que debe añadirse también el ms. 19019 de la Biblioteca Nacional, hermano de su correlativo ms. 19018), que nos remonta a la pasión que compartieron por la figura de Antonio de Nebrija dos sabios bibliófilos ilustrados: el juez, consejero y camarista de Castilla Fernando José de Velasco Ceballos, y el polígrafo Gregorio Mayans y Siscar ${ }^{9}$. El primero, poseedor de una riquísima biblioteca, se hizo en 1766 con un manuscrito nebrisense cuyo hallazgo comunicaba así al amigo:

Por rara casualidad llegó a mis manos un día destos cierto manuscrito en el qual ai tres opúsculos del Mr. ${ }^{\circ}$ A(ntonio). Lebrija: 1, impugnación latina de cierto pasage de Reuchini i de Erasmo. 2, una carta en castellano al cardenal Cisneros sobre la impresión de la Biblia Complutense. I, 3, el Tratado De Asse, pero sin principio ni fin. Lo que participo a Vm. para que esté noticioso de semejante feliz hallazgo, i se sirva avisarme si tendremos disposición de completar el último opúsculo por una parte o por otra, pues lo celebraría ciertamente infinito (Mayans y Siscar 1972-2009, XVI, ep. 404 de 1103-1766, p.320).

\footnotetext{
${ }^{7}$ La confusión de Vallesius por el correcto Salesius se explica por estar cortada la parte superior del manuscrito BAHM 626 (véase la descripción).

${ }^{8}$ Se trata de la carta con que Irusta envía a Velasco el ítem III, esto es, el traslado de la Repetitio de mensuris, «sacado con la misma orthographía y puntuación, y aun con las mismas erratas que tiene el exemplar impreso».

${ }^{9}$ Cf. sobre esta amistad bibliófila la introducción a Mayans y Siscar (1972-2009, XVI). Sobre la biblioteca de Velasco, véanse especialmente Andrés (1995) y Moreno Gallego (1998).
} 
Como se deja ver con nitidez en la correspondencia subsiguiente que Velasco y Mayans sostuvieron entre marzo y junio de $1766^{10}$, los dos primeros opúsculos mencionados son en realidad tres, que se han preservado, con ex libris de Velasco, en el ms. 19019 de la BNE: el tratado contra Reuchlin y Erasmo, la De magis observatio y la Epístola a Cisneros (editados en Gilly 1998). El otro tratado manuscrito, De asse, era en realidad el texto incompleto de la Repetitio sexta de mensuris, y su paradero actual -me refiero lógicamente al manuscrito-es desconocido. Velasco franqueó las cuatro obritas a Mayans, quien identificó la Repetitio y mandó a su hermano Juan Antonio trasladar las tres obras restantes: esa copia se corresponde con los ítems I-III del ms. 626 de Valencia. La curiosidad de Mayans se dirigió muy especialmente a la epístola de Nebrija sobre la Biblia cisneriana, porque justamente por aquellas fechas discutía con el danés Carl Klopstock sobre la solvencia de los textos bíblicos complutenses:

Entre los críticos de Dinamarca i Alemania se ha movido una gran qüestión sobre la entereza i condición de la Biblia Complutense, sobre lo qual me pide D. Carlos Klopstock, capellán de la embajada de Dinamarca en essa corte, algunas noticias; i me parece que será mui del caso comunicarle la carta que V.S. nuevamente ha adquirido del M. ${ }^{\circ}$ Lebrija escrita al cardenal Cisneros; i assí estimaré que V.S. me embíe una copia fiel para quedarme yo con ella i embiar otra, diciendo a quién se deve tan feliz hallazgo (Mayans y Siscar 1972-2009, XVI, ep. 411 de 21-04-1766, p.324) ${ }^{11}$.

Ya leída, la Epístola a Cisneros, que eclipsaba el resto de lo recibido ${ }^{12}$, decepcionó a Mayans por ser demasiado 'burlona' y por no avenirse del todo con su (patriótica) defensa de la Biblia Complutense:

He recibido la carta del $\mathrm{M}^{\circ}{ }^{\circ}$ Lebrija al cardenal Cisneros con las otras dos piezas que la acompañan. Me parece que la carta no deve publicarse, no solamente porque es mui burlona, sino porque disminuye la autoridad de la Biblia Complutense. Pero me aprovecharé de ella para confirmar lo que ya tengo escrito, que el cardenal Cisneros hizo seguir en la impressión los egemplares hebreos griegos i latinos más antiguos. Pues la controversia de los alemanes i dinamarqueses es sobre si aquellos hombres doctos, que intervinieron en su impressión, alteraron o no el texto; i de Lebrija consta lo que ellos digeron en su prefación i el mismo cardenal a León X, que no le alteraron, sino que siguieron los mejores egemplares de la Vaticana, i de las Sinagogas de España i el egemplar escrito con letra góthica que ya tendrá ahora mil años (Mayans y Siscar 1972-2009, XVI, ep. 417 de 13-05-1766, p.329).

Pocos años después, en 1770, era Mayans y Siscar quien proporcionaba inéditos nebrisenses a Velasco. El joven canónigo de Valencia Juan Bautista Hermán había he-

\footnotetext{
${ }^{10}$ Mayans y Siscar (1972-2009, XVI). Son relevantes las ep. 409, 411-413, 416-417, 420-421, 423 y 425-428.

${ }^{11}$ Véase Peset Llorca 1975, p. 206.

12 Para Mayans la Epistola era indudablemente el texto más novedoso, porque ya conocía la Repetitio sexta, y también la Tertia quinquagena, que en su cap. 44 aborda el mismo asunto que el tratado contra Reuchlin y Erasmo (Nebrija 1516, fols. d3v-d4r).
} 
cho saber a Velasco que otro célebre estudioso valenciano, el cronista Agustín de Sales ${ }^{13}$, había regalado a Mayans un «opúsculo de nuestro Lebrija», y Velasco solicitaba prontamente una copia para su colección. Después de insistir una vez más, Fernando José de Velasco recibió y copió el manuscrito, y a finales de enero de 1771 lo devolvió a su dueño. Creo no equivocarme al identificar este «opúsculo» con el cuaderno del siglo XVI, con ex libris de Sales, que hoy se inserta en el ms. 626 de Valencia: esto es, con el conjunto que forman el De liberis educandis y una Malleoli uita que ya por entonces parecía condenada a ser invisible. El traslado que Velasco encargó son los ítems I-II del ms. 19018 de la BNE.

El itinerario posterior de los escritos de Nebrija en poder de Mayans y Velasco es fácil de trazar. De un lado, la ordenación de la biblioteca mayansiana agrupó los contenidos del actual ms. 626 en un tomito de «Papeles varios» que hacía el número XXIX. Con esa 'signatura' consultaron el volumen Roque Chabás y Marcelino Menéndez Pelayo. Chabás, archivero de la Catedral de Valencia, editó en 1903 el De liberis educandis y la Epístola a Cisneros a partir del manuscrito mayansiano (Chabás 1903a y 1903b); don Marcelino, por su parte, vio el facticio en casa de la marquesa de Cruilles, descendiente de Mayans, y adjuntó un índice somero a sus fichas de la Biblioteca de traductores españoles, que habría de publicarse póstumamente (Menéndez Pelayo 1953, pp.431-432) ${ }^{14}$. Ya depositado en la Biblioteca del Real Colegio Seminario del Corpus Christi, Antonio Mestre Sanchís describió en varios de sus trabajos el catalogado en esta institución como BAHM, ms. 626 (Mestre Sanchís 1981, p.252; y 1986-1987, p.257). Tanto en la descripción de Menéndez Pelayo como en la de Mestre Sanchís asomaba su cabeza, tímidamente, la esquiva y desatendida Malleoli uita. Del lado de Velasco, los que hoy son mss. 19018 y 19019 de la BNE fueron primeramente adquiridos por el abogado y escritor José Fernández Guerra, en cuya biblioteca examinó Bartolomé J. Gallardo, hacia mediados del siglo XIX, el De liberis educandis y la Malleoli uita (Gallardo 1968, núms. 2654 y 2655). El registro bibliográfico de la Vita aparecido en el Ensayo de Gallardo, transmitido también por Lemus y Rubio (Lemus y Rubio 1913, p.114), debió de poner sobre la pista de la obrita a Pascual Galindo y Luis Ortiz, que terminaron por localizar en Madrid el ms. 19018 e incorporaron su hallazgo a esa Aelii Antonii Nebrissensis Opera inedita que, lamentablemente, como se ha comentado ya, siguió siendo en su mayor parte inedita.

\footnotetext{
${ }^{13}$ Mayans y Siscar (1972-2009, XVI, ep. 538 de 14-09-1770, p.398): «Estimaré a V.S. que me haga sacar una copia del opúsculo de nuestro Lebrija que parece le regaló Dn. Agustín Sales -es noticia de nuestro Hermán- para agregarle a las demás obras que poseo de tan clarísimo escritor». Otras epístolas relativas a este intercambio, sin mayores detalles, son las ep. 540-542, 544 y 551-552.

${ }^{14}$ Menéndez Pelayo ofrece la descripción de los contenidos nebrisenses del manuscrito como apéndice; el ítem VII, el Artificium de Pedro Juan Núñez, también se reseña en la ficha $n^{\circ} 352$. Nuestro erudito debió de conocer el manuscrito en su viaje a Valencia de finales de marzo de 1904, aunque es posible que extrajese su descripción de la Biblioteca de D. José Serrano Morales, que sabemos que visitó (en su carteo con Serrano Morales, Menéndez Pelayo se muestra interesado por su colección mayansiana: véase Menéndez Pelayo 19821991, vol. XVI, ep. 589, 597 y 611; vol. XVII, ep. 385 y 529); esta biblioteca poseía (y posee) un Índex de la biblioteca maiansiana por el Marqués de Cruilles (Biblioteca Serrano Morales, mss. 441 y $442=$ Fondo Serrano Morales, núms. 7263-9 y 7263-10).
} 
Cómo llegó a poder de Agustín de Sales el cuaderno quinientista que contiene el De liberis educandis y la Malleoli uita es más difícil, si no imposible, de elucidar. No he hallado ningún dato medianamente útil al respecto ${ }^{15}$. El origen último de todos (o casi todos) los inéditos de Nebrija hubo de ser el arca de escritos autógrafos que a la muerte del maestro permaneció en depósito en Alcalá de Henares, y que fue retirado por la familia en $1523^{16}$. La imprenta que establecieron en Granada Sancho y Sebastián de Lebrija, hijos del humanista, rescató del olvido algunos de estos inéditos, si bien parece que en Alcalá todavía quedó una porción del legado manuscrito nebrisense ${ }^{17}$. Sea como fuere, la letra del cuaderno de Sales, siendo del siglo XVI, no se corresponde con la de ningún otro de los manuscritos contemporáneos conocidos, y hasta que no se aborde un cumplido estudio paleográfico de este material hemos de conformarnos con la idea -demasiado vaga- de que los apógrafos de los escritos originales de Nebrija debieron de ser varios, hechos en distintos momentos y para distintos propósitos ${ }^{18}$. Adelanto, por lo demás, al hilo de estas reflexiones, y antes de pro-

${ }^{15}$ Acaso ofrezca alguna pista, pero no he podido verlo, el Dietario manuscrito de Sales, que se halla en la Biblioteca del Real Colegio Seminario del Corpus Christi de Valencia.

${ }^{16}$ Véase la mejor transcripción de los escritos que en 1523 fueron devueltos a los Nebrija en Jiménez Calvente (1994, pp.37-38).

${ }^{17}$ En 1526 se reorganizaba el depósito (o archivo) de la Universidad de Alcalá, intentando poner orden en arcas, envoltorios de libros y otras menudencias (a 24 de junio, por ejemplo, se libraban fondos a Hernando de Safagún y al licenciado Avilés «para pago de obra que hazen para los caxones de las escrituras del collegio», Archivo Histórico Nacional, Universidades, lib. 814, fol. 150r). En un inventario de bienes de ese año, en el que se registran los libros de la Biblioteca y el depósito, se anota: «Ansy mismo estava con los dichos envoltorios en esta dicha caxa otro enboltorio de cuadernos y libros escriptos de mano de Antonio de Librixa» (Archivo Histórico Nacional, Universidades, lib. 1092, fol. 139v). He comprobado el dato a partir de una noticia de García Oro 1992-1993, vol. II, p.468 (en García Oro y Portela Silva 2006, ahora bien, se edita el documento completo, pero sitúandolo en la visita ordinaria del licenciado Alonso Pérez, entre 1523 y 1524; el texto transcrito ibid., p. 648).

${ }^{18}$ Los autógrafos indubitados de Nebrija son pocos, de extensión y carácter muy diferentes. Ordeno aquí mis noticias, por si alguien competente en paleografía quisiera aprovecharlas. El hológrafo más extenso es el Borg. Lat. 148 de la Ciudad del Vaticano, que contiene los léxicos bíblicos (editados en Nebrija 1950, con reproducción de un folio allí mismo, en los preliminares, y de otro en Exposición del Libro Nebrisense 1946, p. 11). Una muestra de la labor como copista de un Nebrija muy joven se halla en los mss. 2603 y 2265 de la Biblioteca Universitaria de Salamanca ( $c f$. Codoñer 1991), y algún material escaso, también juvenil, alberga el ms. 98-27 de la Catedral de Toledo, que perteneció a nuestro humanista en su época de estudiante (véase Rico 2002, pp. 188193). En un ejemplar de la Repetitio tertia de 1506 (Biblioteca Histórica de la Universidad Complutense, FLL Res. 1277), Nebrija escribió de su puño y letra una breve dedicatoria a Cisneros, y corrigió y anotó el opúsculo (la dedicatoria se reproduce en la Exposición del Libro Nebrisense 1946, p. 16; todo el volumen es ahora accesible en Internet). Deberían escrutarse con atención, por su interés contrastivo, no solo BAHM, ms. 626 y BNE, mss. 19018 y 19019, sino también: el ms. 132 del Colegio de España de Bolonia; la dedicatoria manuscrita de la Apologia de la British Library (C.63.b.38; veáse Abellán de Corona 1988); las glosas alcalaínas que Coroleu advirtió en un volumen de Poliziano (Coroleu 1998); y dos curiosas páginas sobre léxico de aves al final del ejemplar facticio FOA 633 de la Biblioteca Histórica de la Universidad Complutense, que reúne la Repetitio septima y la Tertia quinquagena de 1516. Otros ítems sugeridos a veces como autógrafos me parecen menos probables, pero no está de más consignarlos: el registro del Liber admissionum del Colegio de España (reproducido en Pérez Martín 1979, I, p. 332); una exigua anotación en un ejemplar de la Repetitio sexta (Biblioteca Universitaria de Salamanca, 17072, fols. a4v-a5r); y las profusas apostillas en las Introductiones latinae de 1481 (Biblioteca Nacional de España, Madrid, I-2652; la insinuación es de Galindo y Ortiz, pero en mi opinión son simplemente notas de clase, tomadas por algún alumno, semejantes a las que también existen en los ejemplares de 1482, 1483 y otros). Sobre un manuscrito de Sinesio de Cirene supuestamente traducido 
seguir, que no me caben dudas sobre la autenticidad de la Malleoli uita, no solo por andar como anda, en caligrafía del XVI y yuxtapuesta al De liberis educandis, sino sobre todo por ciertas referencias muy precisas de índole biográfica que, amén de otros pormenores, me empujan a rechazar la sospecha de una posible falsificación.

\section{CONTENIDO DE LA MALLEOLI VITA}

De una forma humorística, la Malleoli uita narra la vida del hijo mayor de Antonio de Nebrija, Marcelo, a quien se retrata como un ser infame, depravado y libidinoso. El prólogo de la Vita promete mostrar la infamia del personaje desde su infancia hasta la edad adulta, aunque la historia se interrumpe abruptamente en el relato del bautizo del niño. La materialidad del manuscrito, una evidente copia a limpio, con señales de haber sido revisada y con más de un folio y medio en blanco tras las últimas palabras, sugiere que el copista transcribió solamente lo que tenía delante, o dicho de otra manera, que el original se hallaba ya incompleto en el siglo XVI. Tal vez se extraviase el final de una obrita considerada a todas luces como un simple divertimento literario, en cuya conservación no se debió de poner mucho empeño; o tal vez Nebrija no llegase a acabarla, hipótesis que se aviene bien con una fecha de composición tardía, según argumentaré enseguida. No es, en cualquier caso, el único escrito del Maestro que conocemos inconcluso. Llegara o no a escribirse en su totalidad, la Vita fue concebida como un relato más extenso: así lo patentizan su disposición formal -un prologus y un liber primus al que deberían haber seguido otros-, y un título mordaz y necesitado de glosa, que no obstante queda explicado solo a medias -en lo que toca a Malleolus, pero no a Ascalaphus ni a commodatarius - en el texto que ha sobrevivido.

Dejando por el momento a un lado el prólogo, la biografía propiamente dicha comienza anunciando al lector que el de Marcelo será un nacimiento extraordinario, sobrenatural, el de un ser horrendo y monstruoso, rodeado de los más funestos presagios. La escena tiene lugar en una aldea cercana a Salamanca, adonde Nebrija, que enseñaba gramática y poética en la universidad, se había retirado con su mujer huyendo de la peste. El año in quo prodigium hoc e tenebris in lucem emersit no puede ser otro que 1479, cuando una veloz propagación de la enfermedad paralizó a partir de agosto el estudio salmantino. Los libros de claustro nos informan de que las clases y lecciones se suspendieron por completo hasta San Lucas, el 18 de octubre, y de que todavía en noviembre se prorrogaba el permiso para que los catedráticos pudieran dejar sustitutos sin ser multados. Nebrija reaparece en Salamanca solo a comienzos de

\footnotetext{
y firmado por Nebrija véase Pérez González (2002). En el ámbito puramente archivístico, contamos con la rúbrica de nuestro humanista en al menos tres documentos notariales, el segundo de los cuales parece también enteramente autógrafo: una escritura de 1513 (Archivo Histórico Provincial de Sevilla, Procotolos, Mateo de la Cuadra, lib. 10, fol. 790v; publicada por Gil Fernández 1991, pp. 277-278); una petición de 1513 al Consejo Real, para que este medie en un pleito con Arnao Guillén de Brocar (Archivo General de Simancas, Cámara de Castilla, Personas, leg. 19; edito y analizo el legajo en un estudio en curso); y una escritura de censo de 1514 (Archivo Histórico Nacional, Universidades, lib. 1, fols. 169-170; extractada en Torre y del Cerro 1945, pp. 209-210).
} 
diciembre ${ }^{19}$. La fecha concuerda con la que, en base a otras fuentes documentales, se ha propuesto para el nacimiento de Marcelo (Martín Baños 2009, pp.17-18).

Cercano ya el tiempo del parto -volvemos a la Vita-, la esposa de Nebrija comparte con su marido la intranquilidad que le ha producido un extraño sueño en el que se ve a sí misma dando a luz un búho. La credibilidad que debe otorgarse a los sueños es el pretexto con que Nebrija introduce un ágil diálogo que, sin dejar de salvaguardar la ortodoxia religiosa, refleja la ambivalencia con que el tema de la oniromancia se aborda en el Renacimiento. La opinión de Nebrija, que defiende que los sueños son inanes y avisa de que la Iglesia recomienda desconfiar de ellos, se ve contrarrestada por los argumentos de la esposa, que saca a relucir la retahíla de sueños proféticos bíblicos normalmente mencionados en contextos semejantes: los del patriarca José y el profeta Daniel del Génesis, el de José, esposo de la Virgen, el de la mujer de Pilatos... La terminología empleada, que deriva de Macrobio, es igualmente la acostumbrada ${ }^{20}$.

El desasosiego de la esposa lleva a Nebrija a consultar sobre el sueño a una judía salmantina, maxima somniorum coniectatrix, que, como ellos, había huido de la peste y se encontraba en la misma aldea. El dictamen de la judía es inequívoco: el sueño es el presagio de la impiedad futura del que está a punto de nacer; como el búho, el niño está llamado a ser noctámbulo, amigo de la oscuridad y el vicio y enemigo de la luz del día y de la honestidad. Nebrija se limita a invocar aquí la simbología clásica y medieval del búho, ave de mal agüero e imagen del pecado. Léase, por recuperar un solo testimonio, el de Rabano Mauro: Bubo tenebris peccatorum deditos et lucem justitiae fugientes significat (De universo, 8.6; PL 111, col. 457) ${ }^{21}$. Esta interpretación alegórica del búho nos permite, además, entender la alusión a Ascálafo del título de la Malleoli uita. Ascálafo, hijo de Aqueronte, fue convertido en búho en castigo por haber revelado que Proserpina había roto el ayuno impuesto por Plutón como requisito para abandonar el mundo de los muertos. La aplicación a Marcelo del mito de Ascálafo no se desarrolla en el texto conservado de la Vita, pero parece claro que el apelativo habría de perseverar en la presentación del hijo-personaje como impenitente y disoluto noctívago. Uno de los versos con que la judía justifica su agüero ante Nebrija se toma justamente del pasaje en el que Ovidio relata la fábula en las Metamorfosis: Ignauus bubo dirum mortalibus omen (Ov.met.5.533-550; también SERV.Aen.4.462). Quizá se buscase adjudicar también a Marcelo la condición de 'parlero' o 'chismoso' -de deforme fiscal de Proserpina lo motejó Góngora- con que el pobre Ascálafo perpetuó su fama en las letras del Siglo de Oro.

\footnotetext{
19 Véase Marcos Rodríguez (1964, núms.1241 y 1243) (en el primero de los claustros, de 3 de agosto, se autoriza a los catedráticos a ausentarse dejando sustitutos; en el segundo, de 14 de agosto, se suspenden todas las clases y sustituciones). En ambos claustros está Nebrija, que no reaparece hasta el de 3 de diciembre ( ${ }^{\circ}$ 1276). El claustro de noviembre mencionado es el $n^{\circ} 1250$.

${ }^{20}$ Véase la nota 13 de la traducción de la Vita. La bibliografía sobre el tema es abundante. Puede leerse una muy clara síntesis en Kagan (1991, pp.56-62). Otra bibliografía de acercamiento: Le Goff (1983), Gregory (1985), Acebrón Ruiz (2004), Gómez Moreno (2008, pp.75-82) y Rose et al. (2011).

${ }^{21}$ Véase asimismo IsID.orig.12.7.39. Sobre el búho en los bestiarios medievales, $c f$. por ejemplo Clark (1992, pp.216-219). Provechoso es también Muñoz Garrigós (1982-1983).
} 
Nacido ya el bebé, Nebrija remata el capítulo de los presagios acudiendo al argumento astrológico. El encargado de confeccionar y descifrar la carta astral de Marcelo es Juan de Salaya (o Selaya), astrólogo y catedrático de la Universidad de Salamanca, de quien aprendemos, gracias a la Vita, que era cuñado de Nebrija ${ }^{22}$. La predicción astrológica es devastadora, hasta el extremo de que el consejo de Salaya para el padre neófito es que se deshaga inmediatamente de su hijo, bien enviándolo ultra sauromatas aut extremos garamantas, o bien sencillamente haciéndolo desaparecer. El juicio de Salaya resulta algo exagerado cuando se confronta con la lectura del horóscopo, que solo muy vagamente vaticina un porvenir de oscuridad y sordidez de vida, y se demora mucho más en advertir de que el niño será formidolosus, timidus, meticulosus. Teniendo en cuenta que el Marcelo real, comendador de la Orden de Alcántara, tuvo como oficio la guerra, se percibe que la intención satírica es subrayar su naturaleza cobarde y pusilánime, en la que es de suponer que se seguiría insistiendo en el resto de la Vita. Amén de algunas observaciones eruditas sobre la primogenitura, lo interesante del episodio del horóscopo es la toma de postura de Nebrija ante el asunto controvertido de la astrología judiciaria. Como en el caso de los sueños, nuestro humanista se decanta resueltamente hacia la más acendrada ortodoxia. Enfrentado a un aciago pronóstico, el Nebrija padre resuelve no aceptar que la condena de su hijo esté ya escrita de antemano, que no quepa margen de maniobra para que Marcelo encuentre, pese a todo, el camino de su salvación. Como es de sobra conocido, la mentalidad renacentista no desdeña el saber astrológico, siempre y cuando no exista colusión ni con la Providencia divina ni con la libertad humana ${ }^{23}$. La confianza nebrisense en el libre albedrío se sustancia en una formulación exquisitamente clasicista -y pa-

\footnotetext{
${ }^{22}$ Nebrija lo sitúa en la aldea y en el mismo alojamiento, es de suponer que por causa de la peste: Erat per id tempus in eodem contubernio cum socero socruque communi Ioannes Saleius, astrologus insignis... Los libros de claustro de Salamanca confirman también la ausencia de Salaya de la universidad entre agosto y noviembre (Marcos Rodríguez 1964, núms. 1235 y 1274). Para este personaje es fundamental Cantera Burgos 1931, pp. 371-373 y 384-389. El detalle cum socero socruque communi concuerda con una referencia de archivo que conozco desde hace tiempo y que aguardaba una interpretación que ahora es más fácil aventurar: en 1530, Sancho de Nebrija, hijo de nuestro humanista, reclamaba un traslado del testamento de su primo Hernando de Salaya, difunto en Panamá (Archivo General de Indias, Audiencia de Panamá 234, lib. 4, fols. 64v65r). Sobre este Hernando de Salaya, licenciado, que pasó a las Indias en 1521 como lugarteniente del gobernador de Castilla del Oro en Panamá, y que murió en 1527, hay abundante documentación americana, y le mencionan crónicas como las de Fernández de Oviedo o Herrera y Tordesillas. Considero, uniendo todos los cabos, que se trata del tercero de los hijos del Juan de Salaya cuñado de Nebrija, sobre los cuales habla Ruiz de Vergara Álava 1661, p.119: «Juan de Salaya, bachiller teólogo, del obispado de Burgos, fue eligido por colegial [de San Bartolomé] en 7 de enero del año de 1459. Estando en el Colegio se graduó de maestro en Teología y fue catedrático de Astrología, y dél se haze mención en las Constituciones. Acabado el tiempo del colegio, salió dél, y se dize casó con una señora muy principal, en quien tuvo por hijos al maestro Salaya, que fue doctor de medicina y catedrático de la misma cátedra de Astrología, y al doctor Salaya, jurista, inquisidor de Toledo y canónigo doctoral de Coria. Y a otro hijo llamado licenciado Salaya, que exerció puestos de justicia en estos reynos, pero no se sabe quáles fueron». El «maestro Salaya» es Sancho de Salaya, también astrólogo (Cantera Burgos 1931, pp.382-383), a quien curiosamente los Nebrija editaron en Granada su versión del Repertorio de los tiempos (1538 y 1543).

${ }^{23}$ Tal vez la presentación más completa, interesante y amena sobre la astrología renacentista sea la de Caro Baroja 1992, II, pp. 159-218 (sin olvidarnos de Thorndike 1941, pp.159-233 ni de Garin 1981, pp.112124). Hay mucha otra bibliografía, claro está: destaquemos los trabajos de Hurtado Torres (1984), Flórez Miguel et al. (1989), y Vicente (2006).
} 
radójicamente pagana- que probablemente debamos retener como una de las claves interpretativas de la Vita: si Marcelo ha de ser bueno o malo, será su genio tutelar, albus o ater, quien lo decida (Bonus ille, an malus sit futurus? In sui genii albi atrique potestate est).

Hasta este punto, la narración de Nebrija mantiene un tono relativamente grave y circunspecto. Salvo por lo hiperbólico y grotesco del planteamiento -la descripción del hijo propio como un monstruo, un portento execrable de la naturaleza-, podría incluso pensarse que nos hallamos sin más ante un escrito reprobatorio. En este primer tramo de la Vita, la deformidad de Marcelo solo es, significativamente, una deformidad moral, interior. A partir de este instante, sin embargo, el relato se torna abiertamente jocoso y desenfadado, y la comicidad se extrae también de la cantera de las deformidades físicas, exteriores. Decidido a dejar vivir a su hijo, Nebrija busca para él una nodriza que pueda amamantarlo. Las posibilidades en la aldea no son muchas, y se ve forzado a tomar una primera ama rustica, torua, truculenta ac plane barbara que, con todo, no puede soportar por muchos días la suciedad del muchacho. La segunda nodriza es aún peor: una meribibula «más beoda que un grano de uva». La potencia burlesca del pasaje solo puede captarse bien si se tienen presentes las recomendaciones clásicas, medievales y renacentistas para la crianza de los hijos, y en concreto son notables los paralelos textuales con el capítulo III del De liberis educandis del propio Nebrija. Médicos, predicadores y humanistas aconsejaban que las madres no renunciasen a dar el pecho a sus hijos, porque la leche era portadora no solo del afecto y el cariño, sino también, al igual que el semen paterno, del carácter y hasta del parecido físico:

Et quemadmodum ad fingendas animi corporisque similitudines vis et natura seminis valet, ita ad eandem rem lactis naturam prodesse dubium non est (Nebrija 1981, p. 98).

De esta creencia se derivaba que, cuando fuese imperioso recurrir a una nodriza, esta debiera ser escogida con todas las precauciones, porque su leche podría degenerar o corromper la buena índole del niño:

Quaenam igitur dementia est hominem bene ingeniatis primordiis inchoatum insiticio hoc degenerique alimento lactis alieni corrumpere?, praesertim si ista quae nutriendo puero adhibetur, $<$ si> serva, si barbara, si improba, si deformis, si impudica, si temulenta est (Ibid., pp. 98-100) ${ }^{24}$.

Tal es precisamente lo que, como envés paródico de estas advertencias, se nos dice en la Vita que ocurre pasado el tiempo con Marcelo: de su primera nodriza 'heredará' la rusticidad y aun ciertos rasgos faciales, y de la segunda la afición a la bebida.

Superada la semana de edad, el bebé ha de ser bautizado, y corresponde a su padre hacerse cargo de los preparativos. Nebrija busca entonces quienes puedan actuar

${ }^{24}$ Cf. específicamente sobre lactancia Cacho Blecua (1988) y Beltrán (2007, pp.63-68). 
como padrinos, y una vez más las circunstancias le impiden encontrar otra cosa que rudos labriegos. Tampoco hay más fortuna con el sacerdote, desconocedor del latín y casi del español mismo, que apenas si sabe leer silabeando y que en lugar de oficiar la ceremonia con el rito bautismal lo hace con el de los esponsales. Con padrinos tan obtusos -recuérdese que son ellos los que asumen el compromiso de educar al niño en la fe cristiana-, y con un patán incompetente como cura, Nebrija confiesa haber dudado siempre si lo mejor no hubiera sido volver a bautizar a su hijo. Para escoger el nombre del niño, el ilustre latinista que es su padre se encomienda a las acreditadamente clásicas sortes vergilianas y, abierto al azar el volumen de las obras de Virgilio, aparece ante los ojos el fragmento del libro VI de la Eneida en que se habla del malogrado Marco Marcelo, hijo adoptivo de Octavia y sobrino de Augusto, muerto en la flor de su edad (VERG.Aen.6.869-883) ${ }^{25}$. Irónicamente, el oráculo virgiliano -en unos versos patéticos que lloran las frustradas esperanzas sucesorias de Roma-constituye un alivio para Nebrija, que presume que su desgracia (es decir, su monstruoso hijo) no habrá de durar mucho.

La confusión ulterior del nombre Marcellus, que pasa a Malleolus en el torpe entendimiento de los padrinos, es digna de un sainete. La costumbre era que los padrinos tomasen en brazos a los ahijados y los llevasen ante la puerta de la iglesia, donde el sacerdote cumplía parte del sacramento, y que fuesen los mismos padrinos quienes concluyeran la ceremonia dentro ${ }^{26}$. Cuando los campesinos regresan del templo, pues, notifican a Nebrija que su hijo ha sido cristianado y que se llama... Malleolus. De nada vale que Nebrija se sorprenda o se indigne, pues el daño ya está hecho y los padrinos ni siquiera entienden que están tergiversando el nombre: Nebrija pronuncia Marcellus y ellos repiten tres y cuatro veces Malleolus, totalmente ignorantes de su error. Resignado, Nebrija termina por convencerse de que se trata de otra señal divina, y de que su Marcellus es fatalmente Malleolus, el malleus universae terrae que profetizó Jeremías, el mazo o martillo que destruirá y causará la perdición de su familia $^{27}$. Los nombres, al fin y al cabo -reflexiona Nebrija-, poseen significado, y casi nunca su concesión es arbitraria. El manuscrito se detiene justo aquí, tras una breve (y quizá truncada) digresión sobre la etimología de los nombres bíblicos ${ }^{28}$.

\footnotetext{
25 Probablemente, Nebrija hace un guiño erudito a la sors (de estos mismos versos) que recibió en el templo Alejandro Severo (Lampr. Alex. 4, 5).

${ }^{26}$ Véase por ejemplo la descripción del ritual en el Sacramental de Sánchez de Vercial, lib II, títs. ix-liii (Sánchez Vercial 1478, fols. c2r-f4r).

${ }^{27}$ Con asiento en el pasaje que cita Nebrija (VvLg.Ier.50.23), toda una tradición patrística identifica el malleus orbis o malleus terrae con una fuerza devastadora y diabólica que, puesta en manos de Dios, sin embargo, persigue y destruye el vicio. Cf. por ejemplo San Agustín: Malleum universae terrae, diabolum voluit intelligi. De ipso malleo in manu Dei posito, id est in potestate Dei, tunduntur ductiles tubae, ut resonent laudes Dei (Avg.in psalm. 97, 6, PL 37, col. 1255).

${ }^{28}$ En forma de pinceladas, Nebrija nutre su relato de motivos y argumentos de peso (los sueños, la astrología, la convencionalidad del lenguaje). Aunque la Vita se interrumpa aquí, no parece que fuera a profundizarse mucho más en el asunto del simbolismo de los nombres, cuyo horizonte bíblico, clásico y medieval (con San Jerónimo y San Isidoro en lugar destacado) está bien narrado en Curtius 1955, pp. 692-699. Casi acabado ya este artículo, descubro que el humanista francés Josse Bade Ascensius publicó en 1523 una Vita de Tomás de Kempis, de apellido germánico (Haemerken o Haemmerlin) latinizado en Malleolus. La Vita se antepone a la edición de Bade de la obra completa de Kempis: $c f$. Renouard (1908, II, pp.260-261). Para mi sorpresa,
} 
En cierto modo, como veremos en el siguiente apartado, el texto conocido de la Vita nos basta para hacernos una idea bastante aproximada de la intención global de todo el opúsculo. Lo irreparable, más bien, es la pérdida del precioso caudal biográfico que, entreverado con la ficción satírica, habría de contener la continuación de esta Malleoli uita. Aparte de algunas coordenadas generales, poco sabemos de la vida de Nebrija en determinados lapsos de tiempo, y la obra completa podría habernos suministrado detalles de sumo interés.

Documentalmente hablando, por ejemplo, uno de los periodos más oscuros es el de la estancia nebrisense en tierras extremeñas, entre 1487 y 1503, al servicio del maestre de la Orden de Alcántara don Juan de Zúñiga. Este magnate no solo patrocinó los estudios de Nebrija, liberándolo de sus obligaciones docentes: procuró asimismo el jugoso beneficio de una encomienda de la Orden para el primogénito del humanista, Marcelo. Otorgada cuando el muchacho era todavía menor de edad, la encomienda obligaba a su titular a conducirse como un monje-soldado, sujeto a los votos de obediencia, pobreza y castidad. La Malleoli uita da muestras suficientes de que el monstruo Marcelo hubo de quebrantar sus votos de forma repetida, y lo que alcanzamos de él por otras vías así lo confirma ${ }^{29}$. Justamente sobre la condición de comendador de frey Marcelo descansa la última de las bromas del título de la Vita: la desfiguración del esperable commendatarius ('comendador') en commodatarius ('comodatario, usufructuario de un préstamo'). Si atendemos al tecnicismo legal del commodatum-contrato de uso de algún bien que se disfruta de balde pero debe restituirse ${ }^{30}$ - este commodatarius podría querer subrayar la vanidad y pompa mundana de la dignidad de comendador; si además tenemos en cuenta el tono chancero de la Vita, el commodatarius probablemente iría cargado de alguna connotación negativa suplementaria: o bien 'malcriado', 'consentido' o 'ingrato' (en tanto que frey Marcelo gozaría de la encomienda sin merecérsela ni haberla ganado a pulso); o bien lisa y llanamente 'manirroro', 'derrochador' o 'aprovechado'. Es una pena que lo incompleto del manuscrito nos prive de esta y otras respuestas.

\section{LA MALLEOLI VITA. INTENCIÓN Y FECHA}

La Malleoli uita es una obrita ciertamente original. Su mezcla desinhibida de biografía e invención la acerca incluso a estos tiempos nuestros en que la narrativa gusta de desdibujar las fronteras entre lo real y lo ficticio. Desde luego no es fácil en-

\footnotetext{
Bade justifica este Malleolus apelando a un significado simbólico (la obra de Kempis resuena como un martillo en los oídos de los herejes, ahuyentándolos), y diserta ampliamente sobre los nombres y sus presagios ocultos. Pese a todo, considero que no es más que una mera coincidencia.

29 Véase Martín Baños (2009). Entre otras cosas, frey Marcelo tuvo cuando menos dos hijos naturales (con mujeres seguramente distintas).

${ }^{30}$ Alfonso X 1807, Partida V, tít. I, ley I, p. 154: «Et la otra manera de préstamo es de qualquier de las otras cosas que non son de tal natura como estas, así como caballo, ó otra bestia, ó libro ó otras cosas semejantes: et á tal préstamo como este dicen en latin commodatum, que quiere tanto decir como cosas que presta un home á otro para usar et aprovecharse della, mas no para ganar el señorio de la cosa prestada».
} 
contrar precedentes directos, latinos o vernáculos, para una semblanza burlesca como la que compone Nebrija, que escribe al modo de un historiador profesional -cronista real para más señas, como él mismo se encarga de recordar-, pero que desde las primeras líneas juega a situar al lector en el terreno de lo inverosímil y lo caricaturesco. Obviamente no son nuevos los procedimientos narrativos empleados (la parodia, el humor, la sátira), ensayados con éxito por tantos humanistas. Con esos mimbres, Nebrija teje en la Malleoli uita una biografía inversa, negativa, el contrafactum festivo de las abundantes vidas de césares, santos, papas o nobles tan del gusto renacentista. No me es posible, por razones de espacio, realizar un detallado estudio literario de la Vita, de modo que terminaré con un par de apuntes más sobre su intencionalidad.

Que Nebrija emplee el código desrealizador de la parodia no impide apreciar que el propósito de la biografía paródica de su hijo es esencialmente moralizante. El género satírico no excluye la voluntad crítica o censoria -antes la presupone, como es bien sabido-, y el prólogo de la Malleoli uita tiene como objetivo primordial, en efecto, orientar al lector en la dirección correcta y abrirle los ojos para evitar que caiga en errores de interpretación. «Que me avenga a relatar por extenso las costumbres corrompidas de mi primogénito -viene a decir Nebrija- no quiere decir que disculpe su conducta, sino más bien que la repruebo. Así como muchas leyes antiguas parecían equivocadas, y a la postre resultaron ser provechosas, del mismo modo yo -continúo parafraseando el prólogo- reprobaré y denostaré a mi propio hijo, en lugar de defenderlo como padre, para dejar constancia de sus desvaríos y aconsejar encarecidamente que no se siga su ejemplo: si la alabanza de la virtud conduce a algunos hacia la virtud, a otros, en cambio, es la pintura viva de la maldad lo que los aparta de la senda del mal». Salvando todas las distancias, que son muchas, el prólogo nebrisense recuerda el prólogo y las primeras estrofas del Libro de buen amor, en que el Arcipreste amonesta a los oyentes para que sepan penetrar la corteza de las burlas y deleites del loco amor, y entiendan bien que su intención «non fue de lo fazer por dar manera de pecar, ni por mal dezir, mas fue por reduçir a toda persona a memoria buena de bien obrar» (Ruiz 2009, p.237).

Nebrija admite dirigirse también de manera específica a los padres, para recomendarles que no críen a sus hijos en la complacencia y la permisividad, de fatales consecuencias. Y esta finalidad educativa nos permite entroncar de nuevo la Vita con el De liberis educandis nebrisense, que ya hemos comprobado es el telón de fondo de la parodia en el episodio de las nodrizas. No juzgo irrelevante, por ello, que en el ms. 626 de Valencia la Vita se haya conservado a continuación de este tratado: ¿se percató el copista (si no fue Nebrija mismo quien lo hizo) de la cercanía de ambas obras y las emparejó en su traslado a limpio? Nótese, en este sentido, que el ms. 626 es probablemente el testimonio más antiguo y completo del De liberis educandis ${ }^{31}$, y tal vez la yuxtaposición de la Vita no sea una mera casualidad.

\footnotetext{
${ }^{31}$ El manuscrito que sirvió como base de la edición de Esteban y Robles (Nebrija 1981) es el mencionado ms. 132 del Colegio de España, Bolonia (fols. 247r-259v). Siendo también del siglo XVI, parece posterior
} 
Aún menos dudosa me parece la relación de la Vita con la obra literaria del propio biografiado, que legó a la posteridad un extenso volumen titulado Triacas, reunión de tres poemas religioso-morales de parejo título e intención: Triaca del alma, Triaca de amor y Triaca de tristes. Aunque no se publicaron hasta 1542, las Triacas comenzaron a gestarse y escribirse en 1518, cuando frey Marcelo se retiró a su encomienda de Brozas (Cáceres) en busca de la paz espiritual, después de haber llevado hasta ese momento una vida agitada, mundana y plena de ambiciones cortesanas ${ }^{32}$. Al menos las dos últimas Triacas, y seguramente también el núcleo de la primera, se redactaron entre 1518 y 1523 , exactamente en los años en que nos consta que el anciano Nebrija pasó largas temporadas de descanso allí en Brozas, en la casa de su hijo, ocupado - la muerte le aguardaba a la vuelta de la esquina, en el verano de $1522-$ en revisar sus diccionarios y sus Introductiones latina ${ }^{33}$. El objetivo de las piadosas Triacas es ofrendar al lector cristiano un remedio o consuelo religioso ante la desesperanza, pero frey Marcelo aspira también a dejar testimonio con ellas del cambio de rumbo que se ha operado en su vida, del abandono del «tráfago y bullicio de la Corte» y el abrazo de una existencia consagrada a la letras y la oración. La conexión con la Malleoli uita se antoja, en consecuencia, muy probable, en tanto que ambas obras sintonizan perfectamente en su propósito. Resulta difícil imaginar, por otro lado, que un escrito como la Vita pudiera haber sido compuesto sin la 'complicidad' de su protagonista, su destinatario natural. Téngase presente que Nebrija no se ocupa de un personaje ajeno y distante, sino de su hijo primogénito, con quien mantiene asiduo contacto y a quien quiere reprender cordial y paternalmente. Una Vita que caricaturiza jocosamente la figura de frey Marcelo y amplifica grotescamente sus excesos solo posee sentido, en mi opinión, cuando frey Marcelo mismo estaba manifestando de forma fehaciente su arrepentimiento, su conversión. Así, si la presentación que Nebrija hace de sí mismo como cronista real sitúa la composición de nuestra obrita en un tiempo posterior a $1509^{34}$, la confrontación con las Triacas y la evolución vital de frey Marcelo nos permite conjeturar que la Malleoli uita se planeó y compuso - tal vez sin llegar a finalizarse- entre 1518 y 1522.

\footnotetext{
a nuestro ms. 626 valenciano: este contiene, en el libro V, un largo párrafo, tachado pero legible (fols. $7 \mathrm{v}-8 \mathrm{r}$ ), que no transcribe aquel (y que no quiso transcribir, tampoco, Chabás 1903b). Además de la copia del XVIII que transmite BNE, ms. 19018, otras copias dieciochescas del De liberis son: BNE, ms. 22051 (adquirido en 1976; se corresponde con el que Kristeller situaba en Londres, en el Robinson Trust, Phillipps Collection: Kristeller 1989, col. 231a); y Abadía de Monserrat, ms. 891. El De liberis merecería, por supuesto, una nueva edición.

${ }^{32}$ Sobre frey Marcelo y la composición y publicación de las Triacas, véase la introducción de Martín Baños 2009.

${ }^{33}$ A este periodo corresponde la escena que refiere el Brocense: «Pues porque mientras él, en mi pueblo de Brozas, donde terminaba el Diccionario y la Gramática, yacía con fiebre en casa de su hijo Marcelo, caballero de la orden de Alcántara, se quejaba, suspirando constantemente, como le oí decir muchas veces a mi padre, de que dejaba la Gramática y el Diccionario sin acabar» (Sánchez de las Brozas 1995, p.37).

${ }^{34}$ Nebrija fue nombrado cronista real por cédula de 21 de marzo de 1509 (editada parcialmente por Rodríguez Villa 1909, $\mathrm{n}^{\circ} 530$, y por Olmedo 1942, p.37).
} 


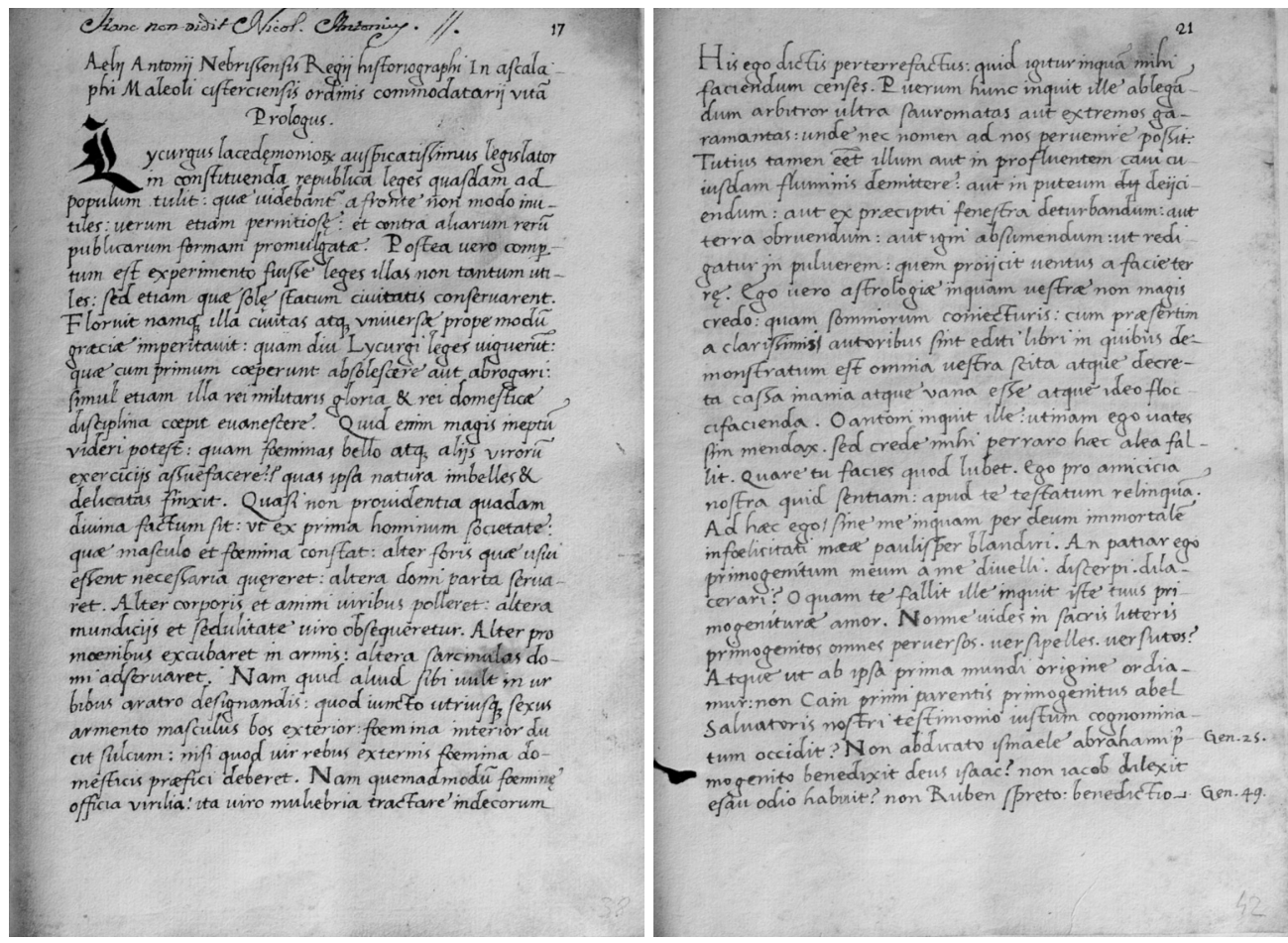

Láminas I y II. Biblioteca del Real Colegio Seminario del Corpus Christi de Valencia, BAHM, ms. 626, fol. 38r y fol. 42r

\section{EDICIÓN Y TRADUCCIÓN}

La base de la edición es el ms. 626 de Valencia, sobre el que las intervenciones han sido mínimas. He mantenido la ortografía del manuscrito, con pocas variaciones reseñables: la expansión de las abreviaturas, la transcripción de la $e$ caudada como ae y la enmienda entre corchetes de apenas dos o tres descuidos (ya advertidos y corregidos en $M$, la copia dieciochesca del ms. 19018 de la BNE). He modernizado la puntuación y, para mayor comodidad, he segmentado en párrafos el texto continuo original. El manuscrito es, como ya se ha dicho, una copia a limpio sobre la que se efectuó una revisión posterior, y así lo demuestran algunos añadidos y correcciones que me ha parecido oportuno señalar mediante los paréntesis triangulares $<>$. Las apostillas marginales del original, que explicitan fuentes bíblicas y clásicas, se han trasladado a nota. Finalmente, conservo la lectura de las citas clásicas, que no siempre coinciden con las lecturas modernas, aunque sí responden, como he podido comprobar, a los textos de al menos alguna edición incunable o post-incunable. 


\section{[MALLEOLI ASCALAPHI VITA]}

\section{[38r] 9 Aelii Antonii Nebrissensis regii historiographi, in Ascalaphi Mal[l]eoli Cisterciensis ordinis commodatarii uitam prologus}

Lycurgus, Lacedaemoniorum auspicatissimus legislator, in constituenda republica leges quasdam ad populum tulit quae uidebantur a fronte non modo inutiles, uerum etiam

5 perniciosae et contra aliarum rerumpublicarum formam promulgatae. Postea uero compertum est experimento fuisse leges illas non tantum utiles, sed etiam quae solae statum ciuitatis conseruarent. Floruit namque illa ciuitas atque uniuersae prope modum Graeciae imperitauit quam diu Lycurgi leges uiguerunt, quae cum primum coeperunt absolescere aut abrogari, simul etiam illa rei militaris gloria et rei domesticae disciplina coepit euanescere.

10 Quid enim magis ineptum uideri potest quam foeminas bello atque aliis uirorum exerciciis assuefacere, quas ipsa natura imbelles et delicatas finxit? Quasi non prouidentia quadam diuina factum sit ut ex prima hominum societate, quae masculo et foemina constat, alter foris quae usui essent necessaria quaereret, altera domi parta seruaret; alter corporis et animi uiribus polleret, altera mundiciis et sedulitate uiro obsequeretur; alter pro moenibus

15 excubaret in armis, altera sarcinulas domi adseruaret. Nam quid aliud sibi uult in urbibus aratro designandis quod iuncto utriusque sexus armento masculus bos exterior, foemina interior ducit sulcum, nisi quod uir rebus externis, foemina domesticis praefici deberet? Nam quemadmodum foeminae officia uirilia, ita uiro muliebria tractare indecorum ${ }^{[38 \mathrm{v}]}$ est. At in Lacedaemoniorum republica foeminae non solum in bellicis rebus usui fuere, sed

20 etiam patriae nonnunquam saluti sunt opitulatae. Quid quod ex operosa laboribusque exercitata muliere miles robustus laborumque patientissimus editur, atqui econtrario ex delicata et molli ignauus, imbellis timidusque procreatur?

Quis non et illud iure possit improbare quod non modo permisit furta, sed etiam inopes ad furandum hortatus est; et quod parum strenue id munus exercentes, si deprehenderentur,

25 uerberibus caedi iussit? At ea res faciebat eos uigilare, die nocteque insidias tendere, captare tempus in quo possent opportune rem exequi, quae omnia non procul absunt a re militari. Complura sunt huius generis, quae Xenophon de Lacedaemoniorum republica tradit, quae si quis nosse cupit, ex ipso petat uolumine opus est.

In Romanorum quoque aristocratia quaedam fuere instituta, quae leuiter intuentibus

30 parum modesta nimiumque perniciosa uidebuntur; euentum tamen rei considerantibus nihil accommodatius atque reipublicae conducibilius fuisse comperietur. Quale est illud licere

prol. 2 Hanc non vidit Nicol. Antonius marg. [la anotación es del siglo XVIII] 


\title{
[VIDA DE MAZUELO ASCÁLAFO]
}

\author{
- Prólogo a la vida de Ascálafo Mazuelo, comodatario de la Orden del Císter, por el \\ cronista real Antonio de Nebrija
}

Licurgo, el más venturoso legislador de los lacedemonios, proveyó a su pueblo, al constituir la república, de ciertas leyes que a primera vista se figuraban no solo inútiles, sino incluso perniciosas y promulgadas en contra de los usos de otras repúblicas. A la larga, sin embargo, se demostró que aquellas leyes no solo habían sido eficaces, sino el verdadero y único sostén de la ciudad. Aquella ciudad, ciertamente, floreció y prevaleció en casi toda Grecia mientras tuvieron vigencia las leyes de Licurgo, porque tan pronto como estas empezaron a caer en desuso o a ser derogadas, empezaron también a desvanecerse la respetada gloria militar y la disciplina interna.

Pues, ¿qué puede resultar más inadecuado que consentir que se adiestren en la guerra y otras actividades masculinas las mujeres, a las que la naturaleza creó débiles y delicadas? Como si la providencia divina no hubiera querido, desde la primera comunidad humana formada por hombre y mujer, que aquel saliese fuera a buscar lo necesario para sobrevivir y esta cuidase en casa de la hacienda; que aquel ejercitase sus fuerzas físicas y espirituales y esta obsequiase al varón con su limpieza y diligencia; que aquel velase armado en las murallas y esta guardase en casa los enseres. ¿Qué otra cosa podía significar, a la hora de trazar las ciudades con el arado, la tradición de uncir una yunta de reses de ambos sexos, el macho para abrir el surco por la parte exterior y la hembra por la parte interior, sino que el hombre debe ocuparse de los asuntos externos y la mujer de los domésticos? ${ }^{1}$ Pues del mismo modo que es indecoroso que la mujer se ocupe de tareas masculinas, también lo es que el hombre lo haga de tareas femeninas. Y, no obstante, en la república espartana las mujeres no solo entendían en los asuntos bélicos, sino que incluso a veces contribuyeron a la salvación de la patria. Si es probable, además, que de una mujer esforzada y acostumbrada a pasar fatigas se engendre un soldado robusto y sacrificado, ¿la delicada y muelle no concebirá, por el contrario, uno indolente, incapaz y medroso?

¿Quién no desaprobará, y con razón, que [Licurgo] no solamente permitiese los robos, sino que incitase a los menesterosos a robar, y que ordenase dar latigazos a quienes eran prendidos por no haber puesto mucho empeño en este deber? Pues bien, esta costumbre hacía que [los espartanos] estuviesen vigilantes y tramasen asechanzas de día y de noche, y que aguardasen la ocasión de poder salirse con la suya; todo lo cual no dista mucho del espíritu militar. Jenofonte cuenta muchas anécdotas de este estilo en su De Lacedaemoniorum republica; si alguien desea conocerlas, búsquelas en ese libro².

También en el sistema aristocrático romano se instituyeron algunas normas que, juzgadas a la ligera, darán la impresión de ser poco apropiadas o demasiado perniciosas; y a pesar de todo, considerando sus efectos, se convendrá en que resultaban enormemente provechosas y oportunas para la república. Una de ellas era la de permitir que cualquiera pudiera acusar de

\footnotetext{
${ }^{1}$ Nebrija alude al rito de fundación de las ciudades etruscas, tal y como lo refiere Varrón (VARRo.ling.5.143; vid. también SERV.Aen.4.212 y 5.575; más lugares clásicos en ThesCRA, V, pp. 344-346). He sido incapaz de encontrar otra fuente que relacione la yunta de ambos sexos con la distribución de los oficios masculinos y femeninos que un comentario sucinto de San Isidoro (IsID.orig.15.2; sí he hallado varios desarrollos semejantes al nebrisense en lexicones, enciclopedias y misceláneas de los siglos XVII y XVIII).

${ }^{2}$ La inspiración principal de todo lo anterior es efectivamente el De Republica et legibus Lacaedemoniorum de Jenofonte, que se divulgó en traducción latina de Francesco Filelfo.
} 
cuique perduellionis diem ad populum uel ad senatum dicere cuicunque uellent, omniaque uitae probra palam obiectare, neque solum fictis sed veris etiam nominibus; sic Caesar in Rabirium et Catonem, sic Cicero in Catilinam et Antonium, sic Salustius in Ciceronem est

35 inuectus, sic alii complures in alios conceptam rabiem euomuere. Sed ea nimirum licentia uel prohibebat homines turpia facere, uel si ex fragilitate humana peccandum ${ }^{[39 r]}$ illis esset, faciebat illos cautiores ne coram aliis turpe aliquid commiterent. Nam lex illa quae praecipit ne in quemquam famosum carmen edatur eo pertinet, ne quicquam falsi obiiciatur. Hinc est illud Horatii: In quem condiderit si quis mala carmina ius est $\mid$ Iudicium; esto, si quis mala,

40 sed bona si quis | Indice condiderit laudatur Caesare; si quis | Obprobiis dignum latrauerit, integer ipse. | Soluentur risu tabulae, tu missus abibis. Nam quid ineptius excogitari potest quam non pudere quosdam turpia facere, atque alia ex parte uetari ne turpiter facta in ipsorum faciem regerantur? Relinquere uestigia suorum scelerum et ne suspicari quidem debere de illis quicquam mali? Deprehendi adolescentem in

45 adolescentula, solum cum sola, papillas attrectantem cum rubore suffusa, et cogi credere quod non uideo quodque oculis cerno, ut non videam?

Haec a me sunt tam longo ambitu repetita ne quisquam miretur cur uitam moresque inquinatissimi iuvenis stilo sim prosecuturus. Id namque $<$ non $>$ tam proderit exemplo ut alii a turpiter faciendo deterreantur, quam probitatem laudando alii ad uirtutis studia

50 excitentur. Simul etiam ne parentes nimia liberorum indulgentia sibi ipsis blanditi, quicquam illorum causa faciant quod alioqui non esset faciendum. Imprimis itaque prosequemur ea quae ante illius ortum portenta praecesserunt. Deinde quae in eius natali atque infantia sunt animaduersa, tum ea quae in puericia quaeque in adolescentia sunt notata. Tum demum ea quae confirmata iam aetate sunt ab eo perpetrata, ut nulla

55 relinquatur eius uitae pars ${ }^{[39 \mathrm{v}]}$ quae uacet infamia. Non quo uelim imputari quae fato, aut corruptae naturae immanitate illi contigerunt, sed quod ad laudem quodammodo atque uituperationem putant, qui de arte dicendi praecepta tradiderunt, ea quae ante nos fuerunt. Vt quod in fabulis legimus oracula praedixisse eum qui ex Thetide nasciturus <erat>, maiorem patre suo futurum. Quodque per insomnia uisa est sibi Ecuba facem parere quae 60 totam urbem incendio corr $<$ um $>$ peret. Pleni quoque sunt huiusmodi mysteriis codices sacri,

prol. 39-41 In quem... abibis] Hor.sat.2.1.82-86

$\mathbf{4 0}$ siquis obprobiis $m s . \quad \mathbf{4 8}$ namque $\operatorname{tam} M \quad \mathbf{6 0}$ corriperet $\mathrm{em}$. 
alta traición ${ }^{3}$ a quien quisiese, ante el pueblo o el senado, y que pudiera exponer públicamente todas las ruindades de la vida del inculpado, y ello bajo nombres reales, y no solo fingidos. Así incriminaron César a Rabirio y Catón, Cicerón a Catilina y Antonio o Salustio a Cicerón; y así otros muchos descargaron su rabia contra sus enemigos. Ahora bien, lo que esta licencia conseguía era que, o bien los hombres no cometieran indignidades, o bien fueran lo suficientemente cautos como para no cometerlas en público, en el caso de dejarse arrastrar al pecado por la fragilidad humana. La ley que prescribía que no se publicase ningún poema compuesto contra alguien famoso se dirigía, en cambio, a evitar que se divulgasen falsedades ${ }^{4}$. De ahí aquello de Horacio: Si alguien compone versos malévolos contra alguien, hay ley y juicio; sí, pero ello si son malos, porque si son buenos y César los juzga y los alaba, o si alguien íntegro ladra al digno de recibir oprobios, la demanda concluirá en risas y tú serás absuelto. Pues, ¿qué puede haber más estúpido que permitir sin rubor que algunos cometan indignidades, y por otro lado impedir que esas indignidades se les puedan reprochar a la cara? Dejan el rastro de sus crímenes, ¿y ni siquiera está permitido sospechar que hayan consumado alguna maldad? Un adolescente es sorprendido sobre una muchacha, ambos a solas, tocando él sus pechos y ella encendida de rubor, ¿y debo ser obligado a creer lo que no veo, y a no ver lo que estoy contemplando con mis propios ojos? ${ }^{5}$

Me he demorado en declarar todas estas cosas para que a nadie maraville que yo vaya a consignar por escrito la vida y la conducta de un joven tan licencioso. El ejemplo será tan beneficioso $^{6}$ para que algunos se abstengan de cometer indignidades cuanto a otros es la alabanza de la honradez lo que los estimula a la virtud. Al mismo tiempo, alentará a los padres que se han dejado ablandar por una excesiva indulgencia para con los hijos a que no hagan con ellos lo que en otras circunstancias no harían. En primer lugar, trataremos de los portentos que precedieron al nacimiento [de Marcelo]; después, de todo aquello que se observó durante el parto y su primera infancia; luego, de lo que llamó la atención en su niñez y en la adolescencia; y, finalmente, de todo lo que él perpetró siendo ya adulto, de modo que no quede trecho alguno de su vida en que falte la infamia. No porque quiera que se le recrimine por igual lo que se debe a la fatalidad y lo que se debe a lo perverso de su naturaleza, sino porque los que enseñaron los preceptos de la retórica juzgaron que las cosas que nos anteceden sirven para la alabanza o la vituperación, dependiendo del caso. Como cuando en las fábulas leemos que un oráculo predijo que el hijo que naciera de Tetis sería superior a su padre ${ }^{7}$. Y aquello de que Hécuba vio en sueños cómo de su vientre salió una antorcha que prendió fuego a toda la ciudad ${ }^{8}$. Los libros sagrados están

\footnotetext{
${ }^{3}$ Cf. Nebrija 2000, p.184: PERDVELIO -ONIS] pro ipsa in Rempublicam aut in principem hostilitate eorum qui hostes patriae iudicati sunt. Vid. también Alfonso X 1807, Partida VII, tít. II, ley III, p.318: «Crimen perduellionis en latin tanto quiere decir en romance como traycion que se face contra la persona del rey, ó contra la pro comunal de la tierra [...]. Otrosi decimos que todo home, quier sea varon ó muger, de buena fama ó de mala, quier sea rico ó pobre, et aun todos aquellos que dixiemos en el título de las acusaciones que non puede acusar á otri, han poderio de lo facer sobre yerro de traycion: et esto les fue otorgado porque fallamos en los libros antiguos que algunas mugeres et viles personas descubrieron trayciones que facien contra los enperadores, et por ende no deben seer desechados los descubridores dellas de qual natura quier que sean».

${ }^{4}$ La Ley de las XII Tablas prohibía la literatura difamatoria (CIC.rep.4.12 y Tusc.4.4).

${ }^{5}$ Esta última frase, que funciona como transición hacia la segunda parte del prólogo, no parece inocente: ¿rememora algún episodio precoz de la vida de Marcelo?

${ }^{6} \mathrm{El}<$ non $>$ que el copista añade en la revisión empeora claramente el sentido del texto; posiblemente sea un error (significativamente, la copia de Mayans lo suprimió), y en la traducción prescindo de él.

${ }^{7}$ El ejemplo lo aduce ya QvinT.inst.3.7.10, y el propio Nebrija lo recuerda en su Rhetorica (cap. XXII).

${ }^{8}$ El sueño de Hécuba antes de dar a luz a Paris se relata en APOLLOD.3.12.5, y en multitud de fuentes posteriores.
} 
ut quod in Malachia propheta praecursor Domini idemque Baptista futurus annunciatur. Nam quae de Iuda proditore circumferuntur, nescio an fabulis annumerari debeant. Sed ea quae ante natalem quaeque in infantia contigerunt infoelicitati, quae in puericia et adolescentia leuitati, quae aetati[s] reliquae iam actae improbitati, quae sequentur per suos

$65<$ annos $>$ immanitati deputanda sunt.

- Malleoli Ascalaphi Cisterciensis ordinis commodatarii uita per Antonium Nebrissensem edita. Liber primus

Consueuere historiarum scriptores notare annos in quibus aliquid insigne monstrosumque contigit.

$5 \quad$ Semiferos partus metuendaque pignora matri,

Moenibus in mediis auditum nocte luporum

Murmur, et attonito pecudes pastore locutas,

Et lapidum duras hyemes, nimboque minacem

Sanguineo rubuisse Iovem, puteosque cruore

10 Mutatos binasque polo concur[r]ere lunas,

Et geminos soles.

Et quae finxere poetae: centauros bimembres, cyclopas unoculos, empusas uni- ${ }^{[40 r]}$ crures. Historici quoque narrant, in extremis partibus orbis homines, uel potius feras hominibus aliqua ex parte similes: sciopodas, monoscelos, astomos, cynocephalos. Quod si

15 cui haec quoque fabulosa uideantur, legat in sacris litteris pygmeos, sirenas, lamias, ululas et onocrotalos.

Nos uero qui ex professione Principisque beneficio Hispanarum Hispaniensiumque rerum historiam scribimus, portentosos hominum partus et miracula naturae monstrisque 
llenos de misterios de este tipo, como cuando en el profeta Malaquías se anuncia la venida del precursor del Señor, y del mismo Bautista (porque todo lo que se cuenta del traidor Judas, dudo si no debe figurar entre las fábulas) ${ }^{9}$. Así, los sucesos anteriores al nacimiento [de Marcelo], y los propios de la primera infancia deben atribuirse a su mala estrella; lo que le aconteció en la niñez y la adolescencia al atolondramiento; el resto de la edad que ya ha gastado a la indecencia; lo que haya de seguir durante su vida a la perversidad.

- Vida de Mazuelo Ascálafo, comodatario de la Orden del Císter, compuesta por Antonio de Nebrija. Libro primero

Los cronistas acostumbraron consignar los años en que sucedía algo señalado y monstruoso:

Partos de seres mitad hombre y mitad bestia, y criaturas que llenan de espanto a su madre; el murmullo de los lobos escuchado en la noche dentro de la ciudad; ovejas que hablan ante el atónito pastor; horribles aguaceros de piedras; un amenazador Júpiter al que tiñe de rojo una sanguinolenta nube; pozos que se trocan en sangre; $y$ dos lunas y dos soles que coinciden en el cielo.

Está también todo aquello que imaginaron los poetas: centauros bimembres, cíclopes de un solo ojo, empusas de una sola pierna. Los historiadores refieren, asimismo, que en los confines de la tierra existen hombres, o por mejor decir fieras solo en parte semejantes a los hombres, que hacen sombra con sus pies, que tienen una sola pierna, que no tienen boca, que tienen cabeza de perro. Y si a alguien estas cosas le parecen fantásticas, lea en las Sagradas Escrituras que hay pigmeos, sirenas, lamias, úlulas y onocrótalos ${ }^{10}$.

Nosotros, que por profesión y por favor del Príncipe escribimos la historia de España y las cosas a ella tocantes ${ }^{11}$, narraremos en su lugar los partos humanos portentosos, los milagros de

\footnotetext{
${ }^{9}$ Nebrija tiene en mente la leyenda medieval de Judas, divulgada, entre otros muchos textos, en la famosa Leyenda dorada de Jacobo de la Vorágine (al comienzo de la historia de San Matías). Influida por el mito de Edipo, la leyenda cuenta que la madre de Judas soñó, estando embarazada, que su hijo sería la perdición de todo el pueblo hebreo. Convencida de la maldad del recién nacido, la madre persuadió al marido para abandonar a la criatura en un cestillo a la orilla del mar. El niño llegó así a la isla de Iscarioth, donde fue adoptado secretamente por su reina, que poco después concibió otro hijo. Dando muestras de su vileza, Judas mortificaba y ofendía continuamente a su hermano menor, hasta el punto de que la reina se vio obligada a hacer público que Judas no era verdaderamente hijo suyo. Furibundo, Judas mató a su hermano y huyó a Jerusalén, donde entró al servicio de Pilatos. Allí, sin ser consciente de lo que hacía, mató a su propio padre, envidioso del huerto que este poseía, y desposó a su propia madre. Sobre la leyenda y su descendencia, $c f$. Baum 1916 y Gutiérrez Carbajo 1993.

${ }^{10}$ El catálogo de monstruos que ofrece Nebrija es una síntesis de los habituales en el mundo antiguo, medieval y renacentista, con envíos inexcusables, además del pasaje de Claudiano, a Plinio (Plin.nat.7.30), Aulo Gelio (GELl.9.4), San Agustín (Avg.civ.16.8) o San Isidoro (IsID.orig.11.3). Para los monstruos bíblicos, tal vez influyese en Nebrija la lista de San Jerónimo (Hier.c. Vigil.1.1, PL 23, cols. 353-354). De entre la vasta bibliografía al respecto, vid. Kappler 1986, Vega Ramos 2002 y Río Parra 2003. De Claudiano puede comentarse que se trata de uno de los autores clásicos más tempranamente leídos por Nebrija, que ya en Italia poseyó un códice con sus obras ( $c f$. Gil Fernández 1965, p.349).

${ }^{11}$ La diferencia entre Hispanus e Hispaniensis la establece, en una glosa al prólogo de sus Introductiones latinae, Nebrija mismo: Nam Hispanum est quod in Hispania atque ex Hispania est, Hispaniense uero quod non penitus Hispanum, sed aut in Hispania ab externis geritur, ut 'bellum Hispaniense', quod ab Romanis in Hispania aut extra Hispaniam ab Hispanis; ut 'Collegium Hispaniense', quod est Bononiae ab immortalis memoraie uiro Aegidio Albornozio SRC Cardinali Hispano fundatum» (Nebrija 1495, fols. a5r-v).
} 
insignia suis in locis narrabimus. Extra ordinem tamen hoc in loco prosequemur monstrum

20 horrendum, ingens, nostro quoque tempore uisum, reddituri tamen postea in historia, cum ad temporum seriem ueniemus. Is putatur ex me genitus non alio argumento quam quod domi meae natus est, atque ex uxore, ex qua bellissimos alios complures liberos genui. Sed neque natura semper gignit quod intendebat, nec semper feriet quodcumque minabitur arcus. Cumque tabificum illum serpentem procreauit terra quem Pythona poetae uocant,

25 illa quidem noluisset, nihilominus tamen in multorum perniciem genitus est. Ita et hic quidem prodiit in lucem inuitis tamen parentibus, quos non magis effinxit neque ex alia materia genitum fuisse putandum est quam pediculos, lendes, ascarides, lumbricos, acaros; quae omnia cum ex nostro corpore gignantur, nihil tamen simile nobis gerunt. Quod si homines mancos, caecos, leprosos ex urbe pellendos, uel potius necandos Aristoteles

30 censet, quid illi faciendum praeciperet qui sit timidus, iners, aeger, solaque libidine fortis? An non in eo exterminan- ${ }^{[40 \mathrm{v}]}$ do apicularum exemplum sequi oportere diceret, quae ignauum fucos pecus a praesepibus arcent?

Annus in quo prodigium hoc e tenebris in lucem emersit fuit pestilentia illa infamis quae, per totam fere Hispaniam grassata, tertiam hominum partem et eo amplius absumpsit.

35 Cumque Salmanticae artem grammaticam simul et poeticam profiteremur, secessimus in uicum agri salmanticensis qui distat ab urbe duodecim milibus passuum Aquilonem uersus, ut adimpleretur in eo illud Hieremiae prophetae oraculum: Ab Aquilone pandetur omne malum. Sub ipsum tempus pariendi, cum uxor exterrita somno euigilasset: "Quae sunt, inquit, mi uir, haec quae me suspensam insomnia terrent? Nam mihi modo uisa sum per

40 quietem bubonem male ominatam uolucrem parere». "Tace, inquam, mulier, neque te ea res moueat, cum praesertim religio nostra somniis non esse credendum praecipiat, quoniam plaerumque inania sunt». "Quomodo, inquit illa, somnia dicis inania? Saepe interfui concionibus istorum qui solent in ecclesiis loqui ad populum, ex quibus non semel audiui Iosephum atque Danielum non modo complura uidisse in somnis, uerum eorum quae alii

45 somniarunt certissimos fuisse coniectores. Angelus quoque non apparuit Ioseph in somnis, dicens illi ne timeret accipere Mariam coniugem suam, et Pilati uxor mittit ad eum qui dicat se multa passam per quietem, ne Christus ab illo damnaretur morti?» «Stulta, inquam, quae te Iosepho et Danielo conferre ${ }^{[41 r]}$ uelis? Nam illa Ioseph uirginis Deiparae coniugis et uxoris Pilati non tam somnia siue insomnia quam uisa, hoc est oramata fuere». «Verum est, 50 inquit, illa insomnia plerumque fallere, sed quae sub auroram proueniunt nunquam temere

23-24 nec... arcus] Hor.ars350 24-25 Cumque.. genitus est] Ov.met.1.438-447. Cf. la discusión de otras fuentes en el cap. 34 de la Tertia quinquagena (Nebrija 1516, fols. c5r-c6r) 28-30 ARIST.Pol.7.16.15; 1335b19-26 32 ignauum... arcent] Verg.georg.4.168 37-38 Ab Aquilone... malum] VvLg.Ier.1.14 39 quae me... terrent] Verg.Aen.4.9. El verso lo discute ya Macrobio (MACr.somn.1.3.6) 46-47 Pilati... morti] Vvlg.Matth.27.19 50-51 Cf. Ov.epist.19.195196: Namque sub aurora, iam dormitante lucerna | Somnia quo cerni tempore uera solent 
la naturaleza y otras monstruosidades dignas de mención. Extraordinariamente ahora, sin embargo, describiremos un monstruo horrendo y descomunal, visto en nuestro tiempo, y volveremos más tarde a la historia, cuando tornemos a la serie cronológica. Un monstruo que se consideró que era hijo mío, con el solo argumento de que nació en mi casa y de la misma mujer que concibió de mí otros hijos más agraciados. Pero la naturaleza no siempre fabrica lo que buscaba, como tampoco el arco alcanza siempre el blanco al que apunta. Cuando la tierra engendró aquella serpiente hedionda que los poetas llaman Pitón lo hizo sin querer, y ello no fue óbice para que causase la perdición de muchos. Tampoco los padres de este monstruo quisieron que naciera así, sin parecérseles, y se hubiera dicho que no fue gestado de otra materia que la de los piojos, las liendres, las ascárides, los gusanos o los ácaros, que, a pesar de que se originan en nuestro cuerpo, no poseen semejanza alguna con nosotros. Si Aristóteles juzga que los mancos, ciegos o leprosos han de ser expulsados de la ciudad, o incluso sacrificados, ¿qué propondría que se hiciera con este que nació medroso, inútil, enfermizo y solamente vigoroso para la lascivia? ¿No diría, acaso, que debería acabarse con él siguiendo el ejemplo de las abejas, que excluyen de las colmenas al indolente enjambre de los zánganos?

El año en que este prodigio emergió de las tinieblas a la luz fue el de aquella infame pestilencia que, diseminada por casi toda España, aniquiló la tercera parte, si no más, de la población. Puesto que dábamos clase entonces de gramática y poesía en Salamanca, nos retiramos a una aldea del campo salmantino que dista de la ciudad unos 12000 pasos hacia el norte ${ }^{12}$, por cumplir con aquel oráculo del profeta Jeremías: Todo el mal vendrá a extenderse desde el norte. Llegado ya el tiempo de parir, mi mujer despertó turbada por un sueño: «¿Qué son -dice-, marido mío, estas pesadillas que me aturden y aterran? Me he visto en sueños dando a luz un búho, esa ave de mal agüero». «Calla, mujer-le digo-, no te inquietes, sobre todo cuando nuestra religión aconseja no creer en los sueños, porque la mayoría de ellos son inanes». «¿Cómo afirmas - dice ella- que los sueños son inanes? He asistido muchas veces a los sermones de quienes suelen en las iglesias predicar al pueblo, y he escuchado, y más de una vez, que José y Daniel no solo vieron multitud de cosas en sueños, sino que también fueron intérpretes certísimos de lo que otros soñaban. ¿Acaso el ángel no se apareció a José en sueños para decirle que no temiera recibir a María por esposa, y acaso la mujer de Pilato no envió a este el recado de que no condenase a Cristo a muerte, porque en sueños había sufrido mucho por él?» «Necia -le digo-, ¿a qué te comparas con José y Daniel? Los de José sobre su esposa la Virgen, Madre de Dios, o los de la esposa de Pilato no eran tanto sueños o pesadillas como apariciones, es decir, oramata $\rangle^{13}$. «Es verdad -dice- que la mayoría de las pesadillas no se cumplen, pero las que

12 De acuerdo con la Repetitio sexta nebrisense, el passus equivale a cinco pies, cuya medida aproximada es de $29 \mathrm{~cm}$; los 12000 pasos del texto equivaldrían, por tanto, a unos 17,5 km, y la aldea al norte de Salamanca de que habla Nebrija debería situarse en la línea que, de oeste a este, trazan Torresmenudas, Forfoleda, Calzada de Valdunciel, Valdunciel, Palencia de Negrilla, Negrilla de Palencia y Pajares de la Laguna.

${ }^{13}$ La clasificación más difundida de los sueños y visiones es la de Macrobio (MACR.somn.1.3.2-10), que distingue entre somnium, uisio (horama en griego), oraculum, insomnium y uisum. El primero, somnium, es el sueño enigmático, pleno de significado pero necesitado de interpretación; la uisio es una aparición soñada y profética, cargada también de implicaciones predictivas; el oraculum es la aparición de carácter divino; insomnium es la reelaboración intrascendente de los anhelos o las preocupaciones de la vigilia; y uisum (phantasma en griego) es la aparición soñada sin alcance futuro. Parece que Nebrija sufre aquí un descuido, porque equipara erróneamente uisum (y no uisio) con horama, cuando en todo el pasaje parece seguir fiel y puntillosamente a Macrobio (nótese cómo se cuida mucho de situar el sueño de su mujer en el terreno de los insomnia, adaptando incluso el mismo paso virgiliano que ya Macrobio recordaba). También en el Dictionarium Latinum Hispanicum se emparejan los términos con sujeción a la doctrina de Macrobio: Orama interpretatur uisio in somno; Visum, por la visión, quae graece phantasma (Nebrija 1512, s. v.). En lo que concierne a los ejemplos bíblicos, presumiblemente se pensase en GrEG.moral.1.8 o en IsID.sent.3.6. 
uisuntur, quale me miseram hoc meum est insomnium. Iniecit animo meo scrupulum».

Confero me ad iudaeam quandam quae ob eandem qua nos causa eodem ex urbe profugerat. Haec erat maxima somniorum coniectatrix, nimirum illius simillima de qua Iuuenalis: Arcanam Iudaea tremens mendicat in aurem, | Interpres legum Solymarum et

55 magna sacerdos, et quod subdit: Qualiacunque uoles Iudaeae somnia uendunt. Expono illi uxoris insomnium. Respondet nefas dirum ex eo partu portendi. «Quodnam, inquam, illud est?» «Nunquamne, inquit, audisti: Ignauus bubo dirum mortalibus omen; et illud: Solaque culminibus ferali carmine bubo | Saepe queri, et longas in fletum ducere uoces? Nam hic si uixerit, semper obambulabit nocturnus; semper appetet solitudines, ne habeat suae

60 nequiciae testes, quorum pudeat». "Atqui bubo, inquam, honestissimos habet oculos, quorum pulchritudinem caeterae aues petant, quod mirari dicitur». «Est ita, inquit illa, sed in tenebris oculatus est, per diem nihil uidet, et qui ambulat in tenebris, odit lucem. Pari modo hic ad honesta splendidaque caecus, ad turpia sordidaque oculatus erit». Discedo inde tristis, nihilque uxori refero.

65 Erat per id tempus in eodem contubernio cum socero socruque communi Ioannes Saleius, astrologus insignis, et qui ex artis suae fide singulari atque propter diuinas praedictiones ma- $\left.\right|^{[41 \mathrm{v}]}$ gnum nomen fuerat nostra aetate consecutus. Cum primum hoc portentum emersit in lucem, arripit astrolabium, acceptoque horoscopo disponit suis in locis septem sydera quae dicuntur errantia, atque ex fixis quindecim, illas quas uocant astrologi

70 ordinis primi; deinde supputat per digitos nescio quid, tandemque in hanc uocem erumpit: «Proh Deus immortalis, inquit, ecquid ego uideo! Non opinor ab orbe condito tam maleficum apotelesma cuiquam mortali contigisse». «Et quodnam, inquam, illud est? Nam et me fecit Vrania poetam, astrologum<que > simul». «Scorpionis, inquit, aculeus in signo ascendente». «At ea, inquam, domus est Martis, eritque bellicosus». «Immo uero, inquit

75 ille, formidolosus, timidus, meticulosus, patieturque terrores quos uocant panicos. Est namque in cacodaemone, hoc est in domo duodecima, quae cadit ab ascendente, quod ipsum uitae quandam obscuritatem, sordesque significat».

${ }^{[42 r]}$ His ego dictis perterrefactus: «Quid igitur, inquam, mihi faciendum censes?» «Puerum hunc, inquit ille, ablegandum arbitror ultra sauromatas aut extremos garamantas, 
sobrevienen al amanecer no deben despreciarse a la ligera, y mi pesadilla, ay de mí, era una de estas, y ha sembrado desasosiego en mi espíritu».

Me dirijo entonces a cierta judía que huyó de la ciudad por el mismo motivo que nosotros. Era una gran intérprete de sueños, en todo semejante a aquella de la que Juvenal escribe: Una temblorosa judía pide limosna susurrando al oído, como intérprete de la leyes de Jerusalén y gran sacerdotisa, y lo que sigue: Las judias te venden los sueños que tú quieras. Le expongo el sueño de mi mujer, y me responde que el nacimiento presagia algo impío y abominable. «¿Cómo es ello?»-le digo. «¿Nunca oíste - dice ella-: El cobarde búho es presagio abominable para los mortales, y aquello otro: Y el solitario búho repetía en los tejados su quejumbroso canto funeral y prolongaba su voz en un gemido? Si el nacido llega a vivir, rondará siempre de noche y anhelará siempre la soledad por no tener testigos que puedan reprocharle su disipación». «Pero el búho -le digo yo- posee unos hermosísimos ojos, cuya belleza embelesa al resto de las aves, algo a lo que se denomina admiración ${ }^{14}$. "Así es -dice-, pero solamente ve en las tinieblas, no percibe nada durante el día, y quien anda de noche odia la luz. De idéntico modo, este será ciego para las cosas honestas y resplandecientes, y tendrá vista para las deshonestas y sórdidas». Me alejo triste de allí, y no le digo nada de esto a mi mujer.

Estaba a la sazón en la misma posada Juan Salaya, con quien yo compartía suegro y suegra, astrólogo insigne que había conseguido gran renombre en nuestro tiempo por la singular fiabilidad de su arte y algunas predicciones de carácter divino ${ }^{15}$. Tan pronto como el portento fue dado a luz, toma él el astrolabio y, examinado el horóscopo, dispone en sus lugares las siete estrellas que llaman errantes, y quince de las fijas, aquellas que los astrólogos llaman de primera magnitud ${ }^{16}$; cuenta después no sé qué con los dedos, y finalmente prorrumpe en un grito: « ¡Oh, Dios inmortal! - dice-, ¡qué es lo que veo! A ningún mortal le ha correspondido en el mundo, según creo, un pronóstico tan maléfico». «¿Y cuál es él? -digo-, pues Urania me hizo poeta, y al tiempo algo de astrólogo». «El aguijón de Escorpio - dice- está en signo ascendente». «Pero -le digo yo- esta es la casa de Marte, y por ello será belicoso». «Muy al contrario - dice-, será asustadizo, medroso, timorato, y sufrirá de esos terrores que denominan pánicos. Se encuentra también en la casa duodécima, o cacodaemon, que cae desde el ascendente, lo que significa cierta oscuridad y sordidez de vida» ${ }^{17}$.

Estremecido por estas palabras le digo: «¿Qué crees que debo hacer?» «Creo - dice- que habría que enviar a este niño más allá de la tierra de los saurómatas o de los remotos garaman-

\footnotetext{
${ }_{14}$ Nebrija transfiere al búho la cualidad que en los tratados zoológicos suele atribuirse a la lechuza (noctua): una suerte de fascinación que seduce al resto de las aves y de la que se aprovechan los cazadores. Léase la traducción latina de Theodoro Gaza de ARIST.HA 9.1, 609a14-16: Sed die uel caeterae auiculae omnes noctuam nimirum circumuolant, quod mirari uocatur, aduolantesque percutiunt; quapropter aucupes ea constituta, auicularum genera multa et uaria capiunt (Aristóteles 1513, fol. 46v). Cf. también SERV.georg.1.403.

${ }^{15}$ Cantera toma de Pellicer la siguiente noticia (Cantera 1931, pp. 387-388): «Un Horrible Eclipse de Sol que huvo en Castilla a diez y Nueve de Julio de 1478, que se vieron todas las Estrellas, a que se siguieron Pestes, Muertes de Pontífices y Príncipes. Y que este Eclipse le avía prevenido el Maestro Zelaya Insigne Filosofo de Salamanca».

16 Las estrellas errantes son los planetas, que, a diferencia de las estrellas fijas, se mueven en el firmamento.

${ }^{17}$ Sin entrar en honduras sobre el horóscopo de Marcelo, la referencia a Escorpio nos permite afinar más su fecha de nacimiento: entre el 23 octubre y el 21 de noviembre de 1479. El signo Escorpio es, de acuerdo con la doctrina astrológica, la casa nocturna de Marte; y en la casa duodécima de la figura genetlíaca (o cacodaemon) se vaticinan los aspectos más negativos de la vida del recién nacido. Cf. FIRM.math.1.17: Malus vero daemon in XII. ab horoscopo signo ponitur, sed Malam fortunam Graeci cacen tychen appellant, Malum daemonem id est [in] XII. ab horoscopo signum cacodaemonem Graeci vocant.
} 
80 unde nec nomen ad nos peruenire possit. Tutius tamen esset illum aut in profluentem caui cuiusdam fluminis demittere, aut in puteum deiiciendum, aut ex praecipiti fenestra deturbandum, aut terra obruendum, aut igni absumendum, ut redigatur in puluerem quem proiicit uentus a facie terrae». «Ego uero astrologiae, inquam, uestrae non magis credo quam somniorum coniecturis, cum praesertim a clarissimis autoribus sint editi libri, in

85 quibus demonstratum est omnia uestra scita atque decreta cassa, inania atque uana esse, atque ideo floccifacienda». "O Antoni, inquit ille, utinam ego uates sim mendax. Sed crede mihi, perraro haec alea fallit. Quare tu facies quod lubet. Ego pro amicicia nostra quid sentiam apud te testatum relinquam». Ad haec ego: «Sine me, inquam, per deum immortalem, infoelicitati meae paulisper blandiri. An patiar ego, primogenitum meum a me

90 diuelli, discerpi, dilacerari?» «O quam te fallit, ille inquit, iste tuus primogeniturae amor. Nonne uides in sacris litteris primogenitos omnes peruersos, uersipelles, uersutos? Atque, ut ab ipsa prima mundi origine ordiamur, non Cain, primi parentis primogenitus, Abel, Saluatoris Nostri testimonio iustum cognominatum, occidit? Non abdicato Ismaele, Abrahami primogenito, benedixit Deus Isaac? Non Iacob dilexit, Esau odio habuit? Non

95 Ruben spreto, benedictio ${ }^{[42 \mathrm{v}]}$ transfertur in Iudam? Non renuente Ioseph Ephraim iunior Manasse grandiori aetate praefertur? Non ordine praepostero Phares posterior prius nascitur? Non minimus filiorum Isai ungitur rex Israel? Non Salomon filius minimus quoque omnium quos genuit Dauid, patre adhuc uiuo, rex designatur? Quid quod pater ille ex Euangelio de adolescentiore filio melius quam de prius genito sentit?» Ego uero inquam:

100 «Ista exempla qu[a]e affers aliud significant quam quod prae se ferunt, uocationem scilicet gentium quae substituendae erant in locum israelitici populi. Nunc uero nemo est qui non primogenito suo faueat. Quare desine me aliorsum impellere quam quo animus ducit. Ego potius nutricem infanti quaeram, spemque meam fouebo. Bonus ille, an malus sit futurus? In sui genii albi atrique potestate est».

105 Erat in eo uico una tantum foemina quae puerum posset alere, rustica, torua, truculenta ac plane barbara, torta comam, labroque tumens ac fusca colore, | Pectora lata iacent mammis, compressior aluo, | Cruribus exilis, spaciosa ac prodiga planta, | Continuis rimis calcanea scissa rigebant. Haec prima infanti porrexit mammam, labrisque lac immulsit. Huius mirum dictu! Postea non tantum mores, sed et oris lineamenta uultusque reddidit.

110 Neque sine causa dictum est ab Elisa, exprobranti barbaros Aeneae mores: Duris genuit te cautibus horrens | Caucasus, hircanaeque admorunt ubera tigres. Quasi non illud

92-93 Cain... occidit] VvLg.Hebr.11.4 93-94 abdicato... Isaac] VVLg.gen.21 94 Iacob... habuit] VvLG.gen.27 y Mal.1.2395 Ruben... Iudam] VVlg.gen.49.3-11 95-96 renuente... praefertur] VVLG.gen.48.17-20 96-97 ordine... nascitur] VVlg.gen.38 97 minimus... Israel] VvLg.I reg.16 97-98 Salomon... designatur] VvLg.III reg.1 98-99 quod pater... sentit] Vvlg.Luc.15.11-32 104 Hor.epist.2.2.186-188. Vid. asimismo Serv.Aen.6.743: Nam cum nascimur, duos Genios sortimur. Unus est, qui hortatur ad bona: alter qui depravat ad mala 106-108 torta... rigebant] Moret.3336 110-111 Duris... tigres] Verg.Aen.4.366-367

94 Isaac] Gen. 25 marg. [en realidad es Vvlg.gen.21] 95 Iudam] Gen. 49 marg. 96 praefertur] Gen. 48 marg. 97 nascitur] Gen. 39 marg. [en realidad es VvLG.gen.38, como corrige $M$ ] 97 Israel] Primo Regum 16 marg. 98 designatur] Tertio Regum 2 marg. [en realidad es VVLG.III reg.1] 109 dictum em. 111 tigres] Ver. 4 Aen. marg. 
$\operatorname{tas}^{18}$, de donde ni su nombre pudiera regresar a nosotros. Claro que quizá sería más seguro arrojarlo al torrente de algún profundo río, o echarlo a un pozo, o despeñarlo desde alguna ventana, o sepultarlo en tierra, o entregarlo al fuego para convertirlo en ceniza que el viento borrase de la faz del mundo». «Yo -le digo- no creo en vuestra astrología más que en las interpretaciones de los sueños, especialmente porque hay libros publicados por los más respetados autores, en los que se prueba que toda vuestra ciencia y todos vuestros fundamentos son hueros, inanes y vanos, y que por tanto no debe concedérseles crédito alguno» ${ }^{19}$. «iOh, Antonio! -dice-, ojalá sea yo un pronosticador embustero. Pero creéme, raramente engaña esta suerte. Haz, pues, lo que gustes. En nombre de nuestra amistad, te declaro lo que pienso». Yo repuse: «Permíteme, por Dios inmortal, un instante para digerir en lo que a mí concierne esta desdicha, pero ¿cómo podré tolerar que mi primogénito sea arrancado de mí, desgarrado, dilacerado?» «¡Cuánto te confunde -dice él- esta pasión tuya por la primogenitura! ¿No ves, acaso, que en las Sagradas Escrituras todos los primogénitos son perversos, mudables, astutos? Por comenzar por el origen mismo del mundo, ¿no mató Caín, primogénito del primer padre, a Abel, señalado como justo en testimonio de Nuestro Salvador? ¿No rechazó Dios a Ismael, primogénito de Abraham, y bendijo a Isaac? ¿No amó a Jacob, y tuvo odio a Esaú? ¿No trasladó su bendición, postergado Rubén, a Judá? ¿No fue antepuesto el joven Efraín a Manasés, de mayor edad, contra el criterio de José? ¿No nació antes, invirtiendo el orden, Fares, que era el [gemelo] posterior? ¿No fue ungido como rey de Israel Isaí, el más pequeño de los hermanos? ¿No fue también designado rey Salomón, el más pequeño de todos los hijos que engendró David, estando aún vivo su padre? ¿Y qué hay de aquel padre del Evangelio que comprende antes a su hijo más joven que al mayor?» Yo le contesto: «Pero estos ejemplos que aduces esconden un significado diferente bajo la superficie: el llamamiento a las naciones que habían de ser puestas en lugar del pueblo israelita ${ }^{20}$. Hoy en día, empero, no hay nadie que no proteja a su primogénito. Así que deja de empujarme hacia una dirección distinta de la que mi corazón desea. Voy a buscar una nodriza para el bebé, y mantendré la esperanza. ¿Será bueno o será malo? La respuesta está en manos de su genio tutelar, blanco o negro»».

Había en aquella aldea una sola mujer que pudiera dar de mamar a un niño, una mujer rústica, torva, grosera y manifiestamente bárbara, de cabello ensortijado, labios gruesos y color fosco; de pecho abundante, tetas caidas y vientre hundido; de piernas flacas y pies anchos y largos, cuyos talones cuarteados y duros estaban surcados por amplias grietas. Esta fue la primera que dio el pecho al niño y que bañó sus labios con leche. Y ¡qué cosa tan asombrosa! Él reproduciría después no solo el carácter, sino hasta los rasgos de la cara de ella. Con razón Elisa dijo a Eneas, reprochándole sus bárbaras costumbres: El horrendo Cáucaso te engendró entre sus escabrosos riscos, y tigres de Hircania te criaron a sus pechos. Como si los pastores no

${ }^{18}$ La expresión, una combinación de IVv.2.1 y Verg.ecl.8.44, es cara a Nebrija, que la utiliza en distintas ocasiones, como en el poema-respuesta al De barbaria fugata de Pedro Mártir de Anglería o la Apologia (vid. Olmedo 1942, pp.124 y 135).

${ }^{19} \mathrm{La}$ «crítica del pensamiento astrológico», en expresión de Caro Baroja, abarca desde el De diuinatione de Cicerón o las Enéadas de Plotino hasta, ya en los tiempos humanistas, las Disputationes aduersus astrologiam diuinatricem de Pico della Mirandola, pasando por los ataques de numerosos Padres de la Iglesia. Véase la nota 23 de la introducción.

${ }^{20}$ La frase de Nebrija compendia la tradición cristiana de la sustitución del pueblo judío por el nuevo Israel, la Iglesia. Los diversos ejemplos bíblicos de pérdida de la primogenitura ilustran cómo Dios traslada a los cristianos la condición de pueblo elegido. Véase VvLg.Rom.9, o los ejemplos del obispo Máximo, Cesáreo de Arles o San Isidoro que pueden espigarse en Blumenkranz 1963, esp. pp.19, 49-50 y 95-98. Cf. asimismo el propio Nebrija, en el comentario a Sedulio: de uocatione gentium et abdicatione Iudaeorum plenum est testamentum uetus (Nebrija 2011, p.496, 190-191). 
exploratum a pastoribus sit, agnos caprino lacte nutritos uillo duriori uellus habere, ${ }^{[43 r]}$ atque econtrario $\mathrm{h}[\mathrm{a}]$ edos ouillo lacte molliori? Sed neque paedorem infantis diu sustinere potuit. Itaque necesse fuit illum miserum ad alteram meribibulam atque uuae acino

115 ebriosiorem transmittere. Dii immortales! Quis hoc posset credere? Non tam ouum ouo simile est qua[m] is etiam natu grandior nutrici suae.

Venit dies lustricus, in quo nomina infantibus indi consueverunt. Is quemadmodum hebraeis fuit octauus, in quo etiam circumcidebantur, ita gentibus fuit septimus. Neque enim antea licebat nomen indere, propterea quod intra id tempus infantes solent

120 conuulsione, hoc est spasmo excipi, neque multum interea illorum saluti sit fidendum. Sed ego neutrum illorum diem expectandum esse putaui, quod eius uitae diffidebamus, propterea quod ex crebro uagitu, singultibusque intestina in scrotum descenderat. Caput quoque obstetricis negligentia distortum cum oculorum procidentia nihil uitale promittebat. Iubeo tamen parari omnia quae initiando infanti erant necessaria; quaero qui interueniant

125 praestites quos uulgus patrinos matrinasque apellat, neque inuenio nisi agricolas quosdam stolidos et moriones. Nam et in hoc misellus hic fuit infoelix, ut nec praestites quidem sortiretur honestos. Iam uero sacerdos ipse initiaturus nihilo distabat a praestitibus. Nam praeter id quod neque latine neque graece sed neque hispane sciebat, uix prima litterarum elementa in syllabas poterat coagmentare et, quemadmodum mihi postea dixerat puer 130 initiorum minister, pro baptismi ${ }^{[43 \mathrm{v}]}$ uerbis sponsaliorum forma est usus, ut mihi saepe in dubium uenerit an iterato illum baptizandum curarem.

Cumque de nomenclatura interrogatus essem, libuit antiquorum more sortes uergilianas experiri. Depromo codicem, admoueo puerum quadrinnulum qui librum aperiat, patefacta est charta ex sexto Aenedis uolumine cuius primum carmen fuit: Ostendent terris hunc

135 tantum fata, nec ultra $\mid$ Esse sinent..., et quod paulo post sequitur: Tu Marcellus eris...; quod tametsi de Augusti Caesaris ex Octauia sorore nepote dictum sit a Vergilio, nihilominus tamen accipio omen, meque ipsum hoc consolari coepi quod aerumnosus hic puer non diu superstes erat futurus, quoniam Vergilianum oraculum dixerat: Ostendent terris hunc tantum fata, nec ultra $\mid$ Esse sinent. Reputans mecum illud Sapientis: Raptus est

140 ne malicia mutaret illius mentem, ut si filio suscepto non fruerer, relinquerem saltem apud posteros aliquod uirilitatis meae argumentum, edico igitur praestitibus atque gerulae nutrici Marcellum esse nomen eius. Qui cum sacerdoti ad aedis sacrae ostium cathezizandus offerretur, interroganti quod esset nomen eius, omnes una uoce respondent: Malleolus, idque identidem repetunt in cathecismo, in adiurationibus, in ipsa denique lustrici fontis

145 immersione. Redeuntes igitur ex ecclesia gratulantur mihi, denunciantque me habere filium christianum, illique ${ }^{[44 \mathrm{r}]}$ inditum esse nomen Malleolo. «Quid malum, inquam, Malleolo? Marcellumne ego uobis praescripsi debere cognominari?» «Et ita, inquiunt, est appellatus». «Quo, inquam, nomine?» Malleolumque terque quaterque illi repetunt.

Obstupui, uocemque repressi, coepique mecum cogitare, non id sine quodam numine

150 factum ut pro Marcello Malleolus uocaretur. Hic enim erat de quo Ieremias propheta cecinit quod futurus erat malleus universae terrae, hoc est patris, matris, fratum, sororum, totiusque rei domesticae pernicies, labes, calamitas. Ex eo quoque exploratum habui de quo

111-113 Quasi... molliori] GELL.12-15 114-115 uuae.. ebriosiorem] CATVL.27.4: ebrioso acino ebriosioris 115-116 ouum... est] Cf. Otto 1890, p. 261 y Erasmo Adag.410 (I, 5, 10) $\mathbf{1 3 4 - 1 3 5}$ Ostendent... sinent] Verg.Aen.6.869-870 135 Tu... eris] Verg.Aen.6.883 139-140 Vvlg.sap.4.11 151 malleus... terrae] VvLg.Ier.50.23

113 molliori] Ex Phauorino marg. 116 quas ms. : quam $M 133$ qui librum q. qui aperiat em. 
supieran por experiencia que los corderos alimentados con leche de cabra dan una lana más áspera, y que los cabritos nutridos con leche de oveja la dan más fina. El caso es que ella no pudo soportar la baba y suciedad del niño, y en consecuencia fue necesario traspasar al pobrecillo a otra ama, más borrachina y beoda que un grano de uva. ¡Dioses inmortales! ¿Quién podría creerlo? Un huevo no es tan semejante a otro huevo cuanto él, ya de mayor, se terminó pareciendo a su nodriza.

Llegó el día del bautizo, en que, según la costumbre, se imponía el nombre a los niños. Si para los hebreos este fue el octavo día, en que también se los circuncidaba, para los gentiles fue el séptimo. No se podía poner nombre antes porque en ese periodo los bebés suelen ser sacudidos por convulsiones, también llamadas espasmos, y no hay demasiadas garantías de que sobrevivan. Yo pensaba que él no llegaría a ninguno de estos dos días, y no confiábamos en que viviera, porque entre frecuentes vagidos y sollozos sus intestinos habían descendido hasta el escroto. Tampoco la cabeza, torcida y con los ojos saltones por negligencia de la comadrona, auguraba su supervivencia. Ordeno, en cualquier caso, que se disponga todo lo necesario para bautizar al niño, y busco a los que habían de intervenir en calidad de protectores, o como el vulgo los llama, padrinos y madrinas, y no hallo sino ciertos labradores mentecatos y necios. En todo tuvo mal fario este desdichado, pues ni siquiera le tocaron en suerte unos padrinos decentes. Y el propio sacerdote que iba a oficiar el bautizo no distaba mucho de los padrinos. No es que no supiera latín o griego, es que no sabía ni español, ni era capaz apenas de silabear las letras, y, como me contó después el monaguillo que ayudó al bautizo, empleó la fórmula de los esponsales en lugar de la del bautismo, de manera que muchas veces he dudado si no debía volverlo a bautizar de nuevo.

Cuando se me preguntó por el nombre, quise seguir la costumbre de los antiguos y recurrí a las suertes virgilianas. Tomo el volumen, pido a un niño de cuatro años que abra el libro, y se muestra una página del libro sexto de la Eneida, cuyo primer verso era: Los hados mostrarán a este a la tierra, pero no harán nada más que mostrarlo..., y lo que poco después sigue: Tú serás Marcelo...; y aunque Virgilio se refería al sobrino del César Augusto, hijo de su hermana Octavia, acepto el augurio, y empieza a aliviarme la idea de que el triste niño no fuese a durar mucho tiempo, porque el oráculo virgiliano había dicho: Los hados mostrarán a este a la tierra, pero no harán nada más que mostrarlo. Considerando aquello del Sabio: Se apresuró para que la malicia no le hiciese cambiar de opinión, y pensando que, aunque no disfrutase de mi hijo legítimo, al menos iba a dejar alguna prueba de mi virilidad para la posteridad, comunico en voz alta a los padrinos y a la palurda nodriza que su nombre ha de ser Marcelo. Ellos, cuando el que había de bautizarse es presentado a las puertas del templo al sacerdote, y este pregunta cuál era su nombre, responden al unísono: «Mazuelo», y lo mismo repiten en el catecismo, en las adjuraciones y, en fin, en la inmersión misma en la pila lustral. Cuando retornan de la iglesia me felicitan y me anuncian que mi hijo es cristiano y que se le ha puesto el nombre de Mazuelo. «¿Qué diantre Mazuelo? -digo yo. ¿No os había indicado que debía llamarse Marcelo?» «Y así se llama»-dicen. «¿Cuál es el nombre?»-digo yo. Y repiten Mazuelo por tres o cuatro veces.

Quedé pasmado, reprimí la respuesta y comencé a cavilar si no obedecería a la voluntad divina que se llamase Mazuelo y no Marcelo. Este era aquel de quien el profeta Jeremías vaticinó que habría de ser el mazo o martillo de toda la tierra, es decir, la perdición, la ruina, la desgracia de su padre, de su madre, de sus hermanos y hermanas, de toda su casa. Corroboré 
saepe dubitaueram, in nominibus inesse plaerumque uim quandam, neque mortali cuiquam nisi per ironiam temere contigisse, ut si Aethiopem appellemus Album siue Cignum,

155 paruam extortamque puellam Europam. An non sacrae litterae hoc sacramento plenae sunt? Vt quod Adam dictus est ab Adama quod interpretatur terra, dicente Scriptura: Donec reuertaris in terram de qua sumptus es, quia puluis es, et in puluerem reuerteris. Eua quoque quod interpretatur uita: Adam, inquit, uocavit nomen uxoris suae Euam, eo quod mater esset cunctorum uiuentium. Cain possesio, ait namque: Eua concepit et peperit Cain,

160 dicens: possedi hominem per Deum. Seth positio: Cognouit, inquit, Adam uxorem suam et peperit filium, uocauitque nomen eius Seth, dicens: posuit mihi Deus semen aliud pro Abel. Nóe consolatio: Lamech, inquit, genuit filium, uocauitque nomen eius Nóe, dicens: iste consolabitur nos ab operibus et laboribus manuum nostrarum. Phaleg diuisio: Heber, inquit, filii duo, nomen uni Phalech, eo ${ }^{[44 \mathrm{v}]}$ quod in diebus eius diuisa sit terra, et alia ad

165 hunc modum innumera. In Nouo quoque Testamento Iesus interpretatur saluator, unde Euangelista: Vocabis, inquit, nomen eius Iesum; ipse enim saluum faciet populum $<$ suum $>$ a peccatis eorum. Cephas Petrus: Vocaberis, inquit, Cephas, quod interpretatur Petrus.

\footnotetext{
154-155 Aethiopem... Europam] Ivv.8.32-34 156-157 Donec... reuerteris] VvLg.gen.3.19. Cf. Nebrija 1950, I, 135; II, 52 158-159 Adam... uiuentium] Vvlg.gen.3.20. Cf. Nebrija 1950, I, 141; II, 794 159-160 Eua... Deum] VvLG.gen.4.1. Cf. Nebrija 1950, I, 616; II, 488 160-161 Cognouit... Abel] VvLg.gen.4.25. Cf. Nebrija 1950, I, 2602; II, 1909 162163 Lamech... nostrarum] VvLg.gen.5.28-29. Cf. Nebrija 1950, I, 2065; II, 1518 163-164 Heber... terra] VvLG.gen.10.25. Cf. Nebrija 1950, I, 2184; II, 1599 (en sus léxicos, Nebrija recoge la doble grafía Phaleg-Phalech, que mantengo) 166167 Vocabis... eorum] Vvlg.Matth.1.21. Cf. Nebrija 1950, I, 1532167 Vocaberis... Petrus] VvLg.Ioh.1.42. Cf. Nebrija 1950, I, 702.
}

157 reuertaris] Tertio marg. 160 Deum] Quarto marg. 161 Abel] Quarto marg. 163 nostrarum] Quarto marg. [en realidad es VVLG.gen.5.28-29] 164 terra] Decimo marg. 167 eorum] Mat. primo marg. 167 Petrus] Io. primo marg. 
asimismo un pensamiento sobre el que a menudo había tenido dudas, a saber: que en la mayoría de los nombres se encierra una especie de significado profundo, y que a nadie le toca un nombre por casualidad, excepto que se trate de una ironía, como si llamamos Albo o Cisne a un etíope, o Europa a una muchacha bajita y contrahecha. ¿No están llenas las Sagradas Escrituras de este misterio? Adán, por ejemplo, proviene de 'Adam', que es 'tierra', y por ello dice la Escritura: Hasta que vuelvas a la tierra de la procedes, ya que polvo eres y al polvo volverás. También está el caso de Eva, que significa 'vida': Adán-dice-llamó a su mujer Eva, por ser la madre de todos los vivientes. Caín es 'posesión', y dice así: Eva concibió y parió a Caín, diciendo: Dios me ha hecho poseedora de un varón. Seth es 'posición': Conoció -dice-Adán a su mujer y parió esta un hijo, y lo llamó Seth diciendo: Dios puso en mí otra semilla en compensación por Abel. Noé es 'consolación': Lamech-dice-engendró un hijo, y lo llamó Noé diciendo: Este nos servirá de consuelo de todos los trabajos y fatigas de nuestras manos. Faleg es 'división': Heber-dice-[tuvo] dos hijos; uno se llamó Faleg, porque en aquellos días se dividió la tierra. Y como estos hay innumerables ejemplos. También en el Nuevo Testamento Jesús se interpreta como 'salvador', y de ahí las palabras del Evangelista: Le llamarás -dice-Jesús, pues salvará a su pueblo de los pecados. Cefas es Pedro: Serás llamado Cefas -dice-, que significa Pedro. 


\section{REFERENCIAS BIBLIOGRÁFICAS}

Acebrón Ruiz, J. (2004), Sueño y ensueños en la literatura castellana medieval y del siglo $X V I$, Cáceres, Universidad de Extremadura.

Alfonso X (1807), Las siete partidas del Rey Don Alfonso el Sabio, cotejadas con varios códices antiguos por la Real Academia de la Historia, Madrid, Imprenta Real, 3 vols.

Abellán de Corona, C. (1988), «A manuscript letter by Antonio de Nebrija», Bulletin of Hispanic Studies 65, 397-401.

Anderson, W.S. (1977), P. Ovidii Nasonis Metamorphoses, Leipzig, Teubner.

ANDRÉs, G. de (1995), «La biblioteca manuscrita del camarista de Castilla Fernando José de Velasco en la Biblioteca Nacional», Cuadernos de Investigación Histórica 16, 143-165.

Aristóteles (1513), De natura animalium libri ix. Eiusdem de partibus animalium libri iiii, etc. (trad. de Theodoro Gaza), Venecia, Aldo Manuzio (BNE, 3/11538).

BAum, P.F. (1916), «The medieval Legend of Judas Iscariot», Publications of the Modern Language Association of America 31, 481-632.

Beltrán, V. (2007), Poética, poesía y sociedad en la lírica medieval, Santiago de Compostela, Universidad de Santiago de Compostela.

Blumenkranz, B. (1963), Les auteurs chrétiens latins du Moyen Age sur les juifs et le judaïsme, París, Mouton \& Co.

CACHO BlecuA, J.M. (1988), «Nunca quiso mamar lech de mugier rafez: (notas sobre lactancia. Del Libro de Alexandre a don Juan Manuel)», en Beltrán, V. (ed.), Actas del I Congreso Internacional de la Asociación Hispánica de Literatura Medieval, Santiago de Compostela, Universidad de Santiago de Compostela, pp.209-224.

Cantera Burgos, F. (1931), «Notas para la Historia de la Astronomía en la España Medieval. El judío salmantino Abraham Zacut», Revista de la Real Academia de Ciencias Exactas, Físicas y Naturales 27, 63-398 (publicado también exento ese mismo año, Madrid, Bermejo).

Caro Baroja, J. (1992), Vidas mágicas e Inquisición, Madrid, Istmo, 2 vols.

ChabÁs, R. (1903a), «Epístola del maestro de Lebrija al Cardenal quando avisó que en el interpretación de las dicciones de la Biblia no mandase seguir al Remigio sin que primero viessen su obra», RABM 8, 493-496.

ChabÁs, R. (1903b), «Aelij Antonij Nebrissensis histobiographi regij de liberis educandis libellus ad Michaelem Almaçanum a libellis, ab aure, a secretis Ferdinandi Regis Aragonum atque utriusque Siciliae ac proinde Hispani orbis moderatoris foeliciter incipitur», RABM 9, 56-66.

Clark, W.B. (ed.) (1992), The medieval Book of Birds. Hugh of Fouilloy's Aviarium, Binghamton, NY, Center for Medieval and Early Renaissance Studies.

Codoñer, C. (1991), «Tres manuscritos de la Biblioteca General Universitaria de Salamanca y su relación con Nebrija», RHT 21, 269-275.

Coroleu, A. (1998), «Poliziano at Alcalá, or a possible witness to Antonio de Nebrija’s lectures on the Silvae», Euphrosyne 26, 253-260.

CurTius, E.R. (1955), Literatura europea y Edad Media latina, México, Fondo de Cultura Económica, 2 vols.

EIsenhut, W. (1983), Catulli Veronensis Liber, Leipzig, Teubner.

ERASMO DE RotTerdam, (1993), Adagiorum chilias prima (Erasmi opera omnia II.1), ed. Van Poll-Van de Lisdonk, M.L, Mann Phillips, M. y Robinson, Ch., Amsterdam, etc., NorthHolland. 
Exposición del Libro Nebrisense. Catálogo Sevilla, XXIII mayo 1946 (1946), s.1., Magisterio Español.

Flórez Miguel, C. et al. (1989), La ciencia del cielo. Astrología y filosofía natural en la Universidad de Salamanca (1450-1530), Salamanca, Caja de Ahorros de Salamanca.

GAllaRdo, B.J. (1968), Ensayo de una biblioteca española de libros raros y curiosos, coord. y aumentados por Remón Zarco del Valle, M. y Sancho Rayón, J., Madrid, Gredos, 4 vols. (original de 1863-1889, Madrid, M. Rivadeneyra).

García Oro, J. (1992-1993), El Cardenal Cisneros. Vida y empresas, Madrid, Biblioteca de Autores Cristianos, 2 vols.

García Oro, J. y Portela Silva, M.J. (2006), Visitas ordinarias a la Universidad de Alcalá de Henares en el siglo XVI, Santiago de Compostela, El Eco Franciscano.

GARIN, E. (1981), Medioevo y Renacimiento, Madrid, Taurus.

Gil FernÁndez, J. (1965), «Nebrija en el Colegio de los Españoles en Bolonia», Emerita 33, 347-350.

GIL Fernández, J. (1991), «La enseñanza del latín en Sevilla en la época del Descubrimiento», Excerpta Philologica 1, 259-280.

GiLly, C. (1986), «Una obra desconocida de Nebrija contra Erasmo y Reuchlin», en REVUELta Sañudo, M. y Morón Arroyo, C. (eds.), El erasmismo en España, Santander, Sociedad Menéndez Pelayo, pp. 194-218.

GILly, C. (1998), «Otra vez Nebrija, Erasmo, Reuchlin y Cisneros», BSCC 74, 257-344.

Gómez Moreno, A. (2008), Claves hagiográficas de la literatura española (del Cantar de mio Cid a Cervantes), Madrid-Fráncfort, Iberoamericana-Vervuert.

Gregory, T. (1985), I sogni nel medioevo, Roma, Edizione dell'Ateneo.

Gutiérrez Carbajo, F. (1993), «La leyenda de Judas y sus variantes», en Romera, J., LoRENTE, A. y Freire, A.M. (eds.), Ex Libris. Homenaje al profesor José Fradejas Lebrero, Madrid, UNED, II, pp. 805-819.

Hall, J.B. (1985), Claudii Claudiani Carmina, Leipzig, Teubner.

Hurtado Torres, A. (1984), La Astrología en la Literatura del Siglo de Oro. Índice bibliográfico, Alicante, Instituto de Estudios Alicantinos.

JimÉnez CALVEnTE, T. (1994), «Nebrija en los Virorum Doctorum Elogia de Paulo Jovio», RFE 74, 41-70.

Kagan, R. L. (1991), Los sueños de Lucrecia. Política y profecía en la España del siglo XVI, Madrid, Nerea.

KAPPLER, C. (1986), Monstruos, demonios y maravillas a fines de la Edad Media, Madrid, Akal.

KRISTELLER, P.O. (1983), Iter Italicum. A finding list of uncatalogued or incompletely catalogued humanistic manuscripts of the Renaissance in Italian and other libraries, vol. 3: Alia itinera. Australia to Germany, Londres-Leiden, The Warburg Institute-E.J. Brill.

KRISTELleR, P.O. (1989), Iter Italicum. A finding list of uncatalogued or incompletely catalogued humanistic manuscripts of the Renaissance in Italian and other libraries, vol. 4: Alia itinera II. Great Britain to Spain, Londres-Leiden, The Warburg Institute-E.J. Brill.

Kroll, W. et al. (1897-1913), Iulii Firmici Materni Matheseos libri VIII, Leipzig, Teubner, 2 vols.

LE GofF, J. (1983), «Los sueños en la cultura y la psicología colectiva del Occidente medieval», en Tiempo, trabajo y cultura en el Occidente medieval, Madrid, Taurus, pp. 282-288.

LEMUS Y RuBio, P. (1913), «El maestro Elio Antonio de Lebrixa II», Revue hispanique 29, 13-120.

Marcos Rodríguez, F. (1964), Extractos de los libros de claustros de Salamanca. Siglo XV (1464-1481), Salamanca, Universidad de Salamanca. 
Miscelánea Nebrija $(1945)=$ RFE, 29 =Emerita 13 (la Miscelánea Nebrija se reimprimió también exenta en 1946).

MARTín BAÑos, P. (2007), «Frey Marcelo de Lebrija (1479?-1543), primogénito del humanista Antonio de Nebrija. Ensayo bio-bibliográfico (I)», REE 63, 617-654.

MARTín BAÑos, P. (2008), «Frey Marcelo de Lebrija (1479?-1543), primogénito del humanista Antonio de Nebrija. Ensayo bio-bibliográfico (II). Las Triacas», REE 64, 687-713.

Martín BAÑos, P. (ed.) (2009), Las Triacas de Marcelo de Lebrija. Triaca del alma, Triaca del amor \& Triaca de tristes, San Millán de la Cogolla, CiLengua, 2009.

Mayans y Siscar, G. (1972-2009), Epistolario, Valencia, Ayuntamiento de Oliva, 24 vols.

MenÉndez Pelayo, M. (1953), Biblioteca de traductores españoles, ed. preparada por Sánchez Reyes, E., vol. III, Santander, CSIC.

Menéndez Pelayo, M. (1982-1991), Epistolario, ed. de Revuelta Sañudo, M., Madrid, Fundación Universitaria Española, 23 vols.

Mestre SAnChís, A. (1981), «Los humanistas españoles del XVI en la religiosidad de los ilustrados valencianos», HSacr 33, 229-273.

Mestre SAnchís, A. (1986-1987), «Manuscritos de humanistas e historiadores (s. XV-XVII) conservados en el fondo mayansiano del Patriarca», Revista de Historia Moderna. Anales de la Universidad de Alicante 6-7, 255-264.

Moreno Gallego, V. (1998), «Burocracia y cultura libraria en el XVIII: el Camarista Velasco y su gran biblioteca», Trabajos de la Asociación Española de Bibliografía 2, 351-382.

MuÑOZ GARRIGÓs, J. (1982-1983), «Las rapaces nocturnas: del mito a la lengua», AUM 41, pp. 271-297.

Nebrija, A. de (1481), Introductiones latinae, Salamanca, [A. de Porras] (BNE, I-2652).

NebriJA, A. de (1495), Introductiones latinae, Salamanca, [J. de Porras] (Biblioteca Colombina, Sevilla, 60-2-3).

NeBriJA, A. de (1512), Dictionarium Latinum Hispanicum, Burgos, F. de Basilea (BNE, R/7693).

NeBRIJA, A. de (1516), In quinquaginta sacrae scripturae locos non uulgariter enarratos. Tertia quinquagena [Alcalá de Henares, A. G. de Brocar] (Biblioteca de la Universidad de Murcia, S-B-3767).

Nebrija, A. de (1946), Gramática castellana, ed. de Galindo Romeo, P. y Ortiz Muñoz, L., Madrid, Talls. de D. Silverio Aguirre y de Gráficas Reunidas, 2 vols.

Nebrija, A. de (1950), Nebrissensis Biblica, ed. de Galindo Romeo, P. y Ortiz Muñoz A., Madrid, CSIC.

NebriJA, A. de (1981), La educación de los hijos, est., ed., trad. y notas por Esteban, L. y Robles, L., Valencia, Universidad.

Nebrija, A. de (2000), Iuris civilis lexicon, intr. y ed. de Perona, J., Salamanca, Universidad de Salamanca.

Nebrija, A. de (2006), Rhetorica, intr., ed. crít. y trad. de Lorenzo, J., Salamanca, Universidad de Salamanca.

Nebrija, A. de (2011), Comentario al 'Carmen Paschale'y a dos himnos de Sedulio, ed. Yarza Urquiola, V., Salamanca, Universidad de Salamanca.

OdRIOZOLA, A. (1946), «La caracola del bibliófilo nebrisense. Extracto seco de bibliografía de Nebrija en los siglos XV y XVI», Revista de Bibliografía Nacional 7, 1-114 (tirada aparte, Madrid, Imprenta Blass, 1947).

Olmedo, F. G. (1942), Nebrija (1441-1522). Debelador de la barbarie, comentador eclesiástico, pedagogo y poeta, Madrid, Editora Nacional. 
Отто, A. (1890), Die Sprichwörter und sprichwörtlichen Redensarten der Römer Leipzig, Teubner (reed. Hildesheim, Olms, 1968).

Pérez GonzÁlez, M. (2002), «Traducciones humanísticas de El elogio de la calvicie de Sinesio de Cirene», en Maestre Maestre, J.M., Charlo Brea, L. y Pascual Barea, J. (eds.), Humanismo y pervivencia del mundo clásico. Homenaje al profesor Antonio Fontán, IV, Madrid, Ediciones del Laberinto, 2002, pp. 1677-1692.

Pérez Martín, A. (1979), Proles aegidiana, Bolonia, Real Colegio de España, 4 vols.

Peset Llorca, V. (1975), Gregori Mayans i la cultura de la il.lustració, Barcelona, Curial. $P L=$ Migne, J.-P. (ed.) (1841-1864), Patrologiae cursus completus... Series latina, París, Migne, 221 vols.

Renouard, P. (1908), Bibliographie des impressions et des oeuvres de Josse Badius Ascensius, imprimeur et humaniste 1462-1535, París, Paul \& Guillemin, 3 vols.

Rico, F. (2002), «El Nuevo Mundo de Nebrija y Colón», en Estudios de literatura y otras cosas, Barcelona, Destino, pp. 179-213.

Río PARRA, E. (2003), Una era de monstruos. Representaciones de lo deforme en el Siglo de Oro español, Madrid-Frankfurt am Main, Iberoamericana-Vervuert.

RodrígueZ Vila, A. (1909), «Un cedulario del Rey Católico (1508-1509)», BRAH 54, 375 414, 518-525; 55, 137-272, 325-352, 369-406.

Rose, S.V. et al. (eds.) (2011), Los sueños en la cultura iberoamericana (siglos XVI-XVIII), Madrid, CSIC.

RuIz, J., arcipreste de Hita (2009), Libro del Arcipreste (Libro de buen amor), ed. crítica de Zahareas, A.N. y Pereira, O., Madrid, Akal.

Ruiz de Vergara Álava, F. (1661), Vida del Illustríssimo señor don Diego de Anaya Maldonado, Arzobispo de Sevilla, fundador del Colegio Viejo de San Bartolomé, y noticia de sus varones excelentes, Madrid, Diego Diaz de la Carrera.

Sánchez de las Brozas, F., Minerva, ed. de Sánchez Salor, E. y Chaparro Gómez, C., Cáceres, Universidad de Extremadura.

SÁnchez de Vercial, C. (1478), Sacramental, Sevilla, A. Martínez, B. Segura y A. del Puerto (BNE, I-1353).

ThesCRA = Thesaurus cultus et rituum antiquorum (2005-2005), Los Ángeles, Getty Publications, 5 vols.

ThILO, G. y Hagen, H. (1881-1887), Servii Grammatici qui feruntur in Vergilii carmina commentarii, Leipzig, Teubner, 1881-1887, 3 vols.

Thorndike, L. (1941), A History of Magic and Experimental Science, vol. V, Nueva York, Columbia Univ. Press.

Torre y del Cerro, A. de la (1945), «La casa de Nebrija en Alcalá de Henares y la casa de la imprenta de la Biblia Políglota Complutense», en Miscelánea Nebrija $(=R F E, 29=$ Emerita, 13), pp. 175-212.

Vega Ramos, M. J. (2002), Los libros de prodigios en el Renacimiento, Bellaterra, Universidad Autónoma de Barcelona.

ViCENTE, L. M. (2006), Estrellas y astrólogos en la literatura medieval española, Madrid, Ediciones del Laberinto.

WiLlis, J. (1963), Ambrosii Theodosii Macrobii Commentarii in somnium Scipionis, Leipzig, Teubner. 